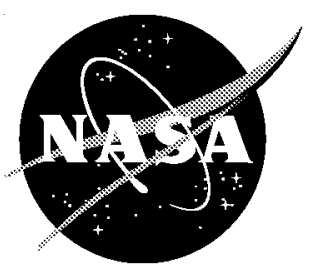

\title{
Flush Airdata Sensing (FADS) System Calibration Procedures and Results for Blunt Forebodies
}

Brent R. Cobleigh, Stephen A. Whitmore, and Edward A. Haering, Jr.

Dryden Flight Research Center

Edwards, California

Jerry Borrer

Johnson Space Center

Houston, Texas

\section{Eric Roback}

Langley Research Center

Hampton, Virginia

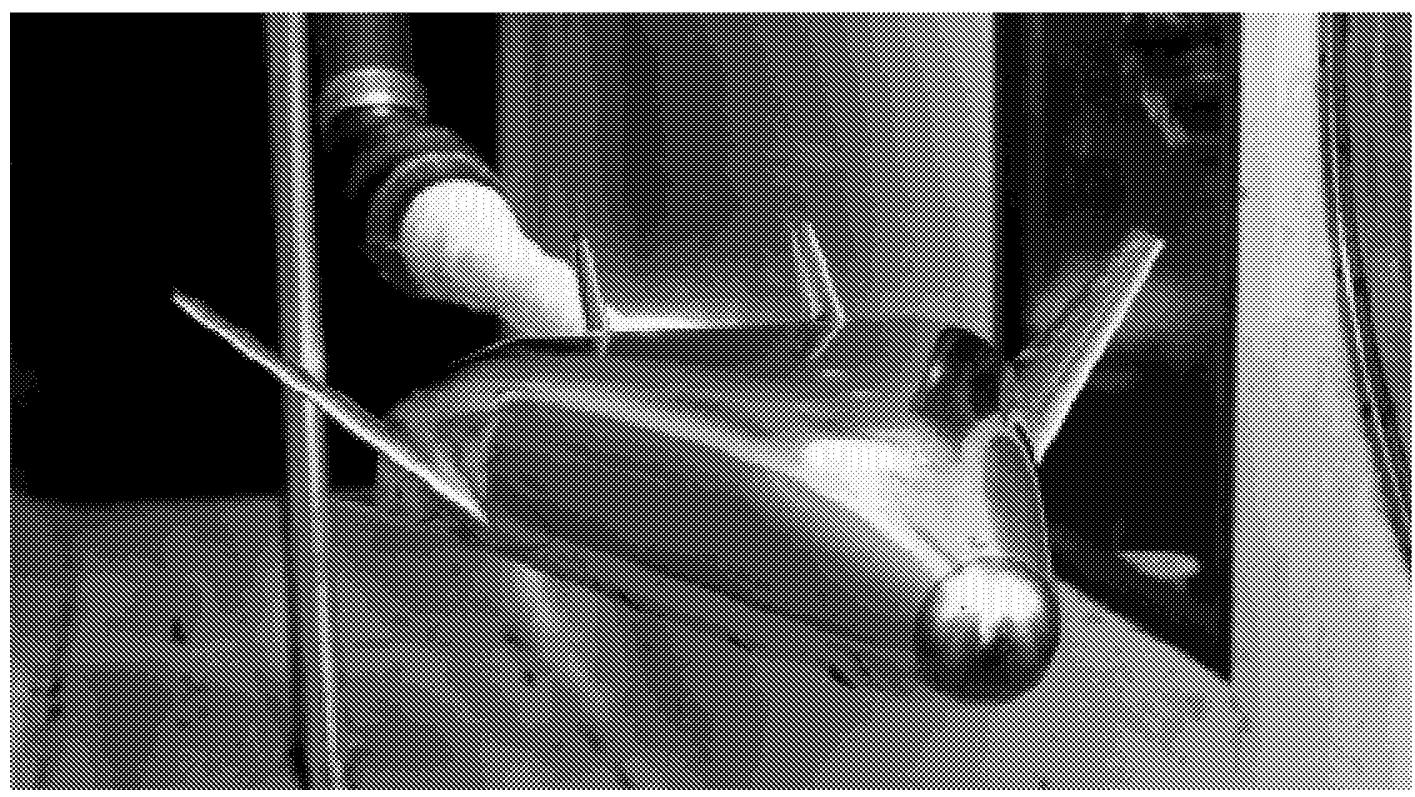

November 1999 


\section{The NASA STI Program Office ... in Profile}

Since its founding, NASA has been dedicated to the advancement of aeronautics and space science. The NASA Scientific and Technical Information (STI) Program Office plays a key part in helping NASA maintain this important role.

The NASA STI Program Office is operated by Langley Research Center, the lead center for NASA's scientific and technical information. The NASA STI Program Office provides access to the NASA STI Database, the largest collection of aeronautical and space science STI in the world. The Program Office is also NASA's institutional mechanism for disseminating the results of its research and development activities. These results are published by NASA in the NASA STI Report Series, which includes the following report types:

- TECHNICAL PUBLICATION. Reports of completed research or a major significant phase of research that present the results of NASA programs and include extensive data or theoretical analysis. Includes compilations of significant scientific and technical data and information deemed to be of continuing reference value. NASA's counterpart of peer-reviewed formal professional papers but has less stringent limitations on manuscript length and extent of graphic presentations.

- TECHNICAL MEMORANDUM. Scientific and technical findings that are preliminary or of specialized interest, e.g., quick release reports, working papers, and bibliographies that contain minimal annotation. Does not contain extensive analysis.

- CONTRACTOR REPORT. Scientific and technical findings by NASA-sponsored contractors and grantees.
- CONFERENCE PUBLICATION.

Collected papers from scientific and technical conferences, symposia, seminars, or other meetings sponsored or cosponsored by NASA.

- SPECIAL PUBLICATION. Scientific, technical, or historical information from NASA programs, projects, and mission, often concerned with subjects having substantial public interest.

- TECHNICAL TRANSLATION. Englishlanguage translations of foreign scientific and technical material pertinent to NASA's mission.

Specialized services that complement the STI Program Office's diverse offerings include creating custom thesauri, building customized databases, organizing and publishing research results ... even providing videos.

For more information about the NASA STI Program Office, see the following:

- Access the NASA STI Program Home Page at http://www.sti.nasa.gov

- E-mail your question via the Internet to help@sti.nasa.gov

- Fax your question to the NASA Access Help Desk at (301) 621-0134

- Telephone the NASA Access Help Desk at (301) 621-0390

- Write to:

NASA Access Help Desk

NASA Center for AeroSpace Information 7121 Standard Drive

Hanover, MD 21076-1320 


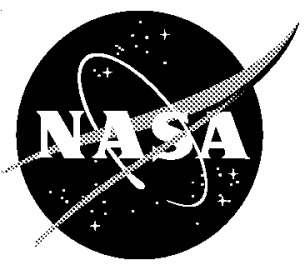

\section{Flush Airdata Sensing (FADS) System Calibration Procedures and Results for Blunt Forebodies}

Brent R. Cobleigh, Stephen A. Whitmore, and Edward A. Haering, Jr.

Dryden Flight Research Center

Edwards, California

Jerry Borrer

Johnson Space Center

Houston, Texas

V. Eric Roback

Langley Research Center

Hampton, Virginia

National Aeronautics and

Space Administration

Dryden Flight Research Center

Edwards, California 93523-0273 


\section{ACKNOWLEDGMENT}

Cover photo courtesy of NASA Langley Research Center, L97-1039, "X-33 Metal Model Testing in Low Turbulence Pressure Tunnel."

\section{NOTICE}

Use of trade names or names of manufacturers in this document does not constitute an official endorsement of such products or manufacturers, either expressed or implied, by the National Aeronautics and Space Administration.

Available from the following:

NASA Center for AeroSpace Information (CASI)

7121 Standard Drive

Hanover, MD 21076-1320

(301) 621-0390
National Technical Information Service (NTIS) 5285 Port Royal Road Springfield, VA 22161-2171 (703) $487-4650$ 


\title{
FLUSH AIRDATA SENSING (FADS) SYSTEM CALIBRATION PROCEDURES AND RESULTS FOR BLUNT FOREBODIES*
}

\author{
Brent R. Cobleigh, ${ }^{\dagger}$ Stephen A. Whitmore, ${ }^{\ddagger}$ and Edward A. Haering, Jr. ${ }^{\S}$ \\ NASA Dryden Flight Research Center \\ Edwards, California \\ Jerry Borrer" \\ NASA Johnson Space Center \\ Houston, Texas \\ V. Eric Roback ${ }^{\#}$ \\ NASA Langley Research Center \\ Hampton, Virginia
}

\begin{abstract}
$\underline{\text { Abstract }}$
Blunt-forebody pressure data are used to study the behavior of the NASA Dryden Flight Research Center flush airdata sensing (FADS) pressure model and solution algorithm. The model relates surface pressure measurements to the airdata state. Spliced from the potential flow solution for uniform flow over a sphere and the modified Newtonian impact theory, the model is shown to apply to a wide range of blunt-forebody shapes and Mach numbers. Calibrations of a sphere, spherical cones, a Rankine half-body, and the F-14, F/A-18, X-33, $\mathrm{X}-34$, and X-38 configurations are shown. The three calibration parameters are well-behaved from Mach 0.25 to Mach 5.0, an angle-of-attack range extending to greater than $30^{\circ}$, and an angle-of-sideslip range extending to greater than $15^{\circ}$. Contrary to the sharp calibration changes found on traditional pitot-static systems at transonic speeds, the FADS calibrations are smooth, monotonic functions of Mach number and effective angles of attack and sideslip. Because the FADS calibration is sensitive to pressure port location, detailed measurements of the actual pressure port

\footnotetext{
"Patent pending.

Aerospace Engineer, Senior member, AIAA.

Aerospace Engineer, Senior member, AIAA.

$\S_{\text {Aerospace Engineer. }}$

ISenior Systems Engineer.

\#Aerospace Technologist, Senior member, AIAA.

Copyright (C) 1999 by the American Institute of Aeronautics and
} Astronautics, Inc. No copyright is asserted in the United States under Title 17, U.S. Code. The U.S. Government has a royalty-free license to exercise all rights under the copyright claimed herein for Governmental purposes. All other rights are reserved by the copyright owner.
\end{abstract}

locations on the flight vehicle are required and the windtunnel calibration model should have pressure ports in similar locations. The procedure for calibrating a FADS system is outlined.

\section{$\underline{\text { Nomenclature }}$}

a, b, c angle-of-sideslip solution parameters

A, B angle-of-attack solution parameters

$\mathrm{A}^{\prime}, \mathrm{B}^{\prime}, \mathrm{C}^{\prime}$ angle-of-sideslip solution parameters

$\mathrm{C}_{\mathrm{p}}$

$\mathrm{C}_{\mathrm{p}_{\mathrm{c}}}$

$d$

pressure coefficient, $\left(p-p_{\infty}\right) / q_{\infty}$ impact pressure coefficient, $\left(p-p_{\infty}\right) / q_{C}$ diameter

ESP electronic scanning pressure

f ellipsoid fineness ratio, $\frac{\text { major axis }}{\text { minor axis }}$

FADS flush airdata sensing

FPM FADS pressure model

HARV High Alpha Research Vehicle

LMVS Lockheed Martin Vought Systems

M Mach number

n number of ports

NTS National Technical Systems

$p \quad$ pressure

$p_{\infty} \quad$ free-stream static pressure, $\mathrm{lbf} / \mathrm{ft}^{2}$

$p_{t} \quad$ total pressure, $\mathrm{lbf} / \mathrm{ft}^{2}$ 


\begin{tabular}{|c|c|}
\hline$p_{t_{2}}$ & $\begin{array}{l}\text { total pressure behind a normal shock } \\
\text { wave, } \mathrm{lbf} / \mathrm{ft}^{2}\end{array}$ \\
\hline $\mathrm{q}_{1}, \mathrm{q}_{2}, \ldots$ & individual port weightings \\
\hline$q_{C}$ & $\begin{array}{l}\text { impact pressure, } \mathrm{lbf} / \mathrm{ft}^{2} \\
\quad \text { (subsonic } q_{c}=p_{t}-p_{\infty} ; \\
\left.\text { supersonic } q_{c}=p_{t_{2}}-p_{\infty}\right)\end{array}$ \\
\hline$q_{\infty}$ & free-stream dynamic pressure, $\mathrm{lbf} / \mathrm{ft}^{2}$ \\
\hline Q & weighting matrix \\
\hline $\operatorname{Re}$ & Reynolds number \\
\hline SRA & Systems Research Aircraft \\
\hline UPWT & Unitary Plan Wind Tunnel \\
\hline$V$ & velocity \\
\hline W & Taylor series parameter \\
\hline $\mathrm{x}, \mathrm{y}, \mathrm{z}$ & Cartesian coordinates \\
\hline $\mathrm{X}, \mathrm{Y}$ & FADS pressure model parameters \\
\hline$\alpha$ & angle of attack, deg \\
\hline$\alpha_{e}$ & effective, or local, angle of attack, deg \\
\hline$\beta$ & angle of sideslip, deg \\
\hline$\beta_{e}$ & effective, or local, angle of sideslip, deg \\
\hline$\varepsilon$ & shape and compressibility parameter \\
\hline$\varepsilon_{\mathrm{M}}$ & $\varepsilon$ component caused by Mach number \\
\hline$\delta M_{\text {required }}$ & maximum acceptable Mach error \\
\hline$\delta \alpha$ & angle-of-attack flow correction angle, deg \\
\hline$\delta \beta$ & $\begin{array}{l}\text { angle-of-sideslip flow correction angle, } \\
\text { deg }\end{array}$ \\
\hline$\gamma$ & ratio of specific heats ( 1.4 for air) \\
\hline$\Gamma$ & $\begin{array}{l}\text { pressure difference, } \Gamma_{i j}=p_{i}-p_{j} \text {, and so } \\
\text { forth }\end{array}$ \\
\hline$\theta$ & local flow incidence angle, deg \\
\hline$\lambda$ & cone angle of a pressure port, deg \\
\hline$\phi$ & clock angle of a pressure port, deg \\
\hline$\sigma$ & standard deviation \\
\hline \multicolumn{2}{|l|}{ Subscripts } \\
\hline e & effective (or local) angle \\
\hline$i, j, k$ & port indices \\
\hline $\max$ & maximum value \\
\hline ref & reference value \\
\hline
\end{tabular}

\begin{tabular}{|c|c|}
\hline true & true value \\
\hline$\infty$ & free-stream value \\
\hline \multicolumn{2}{|c|}{ Superscripts } \\
\hline ^ & estimate \\
\hline$(m)$ & iteration number \\
\hline $\mathrm{T}$ & matrix transpose \\
\hline-1 & matrix inverse \\
\hline
\end{tabular}

\section{$\underline{\text { Introduction }}$}

The accurate measurement of airdata is critical to the flight control, guidance, and postflight analysis of most modern atmospheric flight vehicles. The entire airdata state can be described by five parameters: Mach number $(\mathrm{M})$, angle of attack $(\alpha)$, angle of sideslip $(\beta)$, either pressure altitude or free-stream static pressure $\left(p_{\infty}\right)$, and the true airspeed. Using these five parameters, all other airdata parameters of interest can be calculated.

Historically, airdata have been measured through the use of intrusive booms or probes that penetrate the flow away from the influence of the vehicle body to measure total and static pressure, angle of attack, angle of sideslip, and free-stream temperature. However, specialized requirements of advanced vehicles make using intrusive conventional airdata measurement systems ${ }^{1}$ highly undesirable. Advanced vehicles include hypersonic vehicles, ${ }^{2}$ for which the heating environment is extremely hostile; stealth vehicles, which require a minimal radar cross section; and high-performance vehicles $^{3}$ that operate beyond the poststall flight regime. For example, the presence of an intrusive airdata noseboom on the X-31 aircraft induced unsteadiness in the primary forebody vortices, causing unwanted lateral instabilities in the poststall flight regime. ${ }^{4,5}$

The flush airdata sensing (FADS) system concept, in which airdata are inferred from nonintrusive surface pressure measurements, was developed to circumvent many of the difficulties with intrusive airdata systems. This method does not require probing of the local flow field to compute airdata parameters, and allows for airdata measurements in flight applications where probe-based systems are no longer viable.

The FADS concept relies on a mathematical model that relates measured forebody surface pressures to the airdata state. The current $\operatorname{method}^{2}$ uses a nonlinear pressure model and a nonlinear solution algorithm to solve for the airdata state from the measured pressures. 
Although the FADS pressure model (FPM) has been validated for a high-performance fighter aircraft forebody $^{3}$ and several simple shapes (for example, cylinder and sphere), the suitability of the model for a wide variety of vehicle shapes has not been established.

The primary objective of this study is to gather a set of forebody pressure data for a series of blunt-body shapes to generally characterize the behavior of the FPM calibration. A set of guidelines is developed to aid the design of future blunt-body FADS systems.

The forebody pressure data have been obtained from five sources: a wind-tunnel test of three simple bluntforebody configurations; a collection of previously published wind-tunnel data for generic blunt-body shapes; wind-tunnel tests of the X-33, X-34, and X-38 hypersonic reentry vehicles; exact potential flow solutions for uniform flow over a cylinder, sphere, and an arbitrarily-oriented ellipsoid; and flight data from the F-14 and F/A-18 aircraft. The nature of the calibration for each of the configurations is evaluated as a function of Mach number, angle of attack, and angle of sideslip. Behavior of the mathematical model is also evaluated at Mach numbers much greater than have been previously tested (a maximum of Mach 5.0), which will directly benefit hypersonic FADS applications that are currently in development (the X-33, X-34, and X-38 vehicles). In addition, the adaptability of the FPM to nonspherical forebody shapes is tested. The results presented demonstrate that the current FADS methodology is universally applicable to blunt-nosed configurations.

A patent has been filed on this NASA invention. Equations (10)-(16) are included in this patent. Note that use of trade names or names of manufacturers in this document does not constitute an official endorsement of such products or manufacturers, either expressed or implied, by the National Aeronautics and Space Administration.

\section{Background and Historical Perspective}

The original flush airdata system prototype was developed for the X-15 program and used a steerableball nose that attempted to nullify upper and lower pressure measurements to determine the stagnation point and the local angle of attack. ${ }^{6}$ The mechanical design of this system was cumbersome, and the analogsteering concept was abandoned after the X-15 program ended.

A subsequent approach, the Space Shuttle entry airdata system, ${ }^{7}$ was developed at the NASA Langley
Research Center (Hampton, Virginia) for the Space Shuttle program. This system used a matrix of fixed static-pressure orifices on the orbiter nosecap. The technique later was adapted to aeronautical applications, and several demonstration programs were performed in the early 1980's at the NASA Dryden Flight Research Center (Edwards, California)., ${ }^{8}$ For these early programs, the sensed pressures were related to the desired airdata parameters using a nonphysical mapping. These tests verified the feasibility of the fixedorifice concept but did not demonstrate real timecapable algorithms for estimating the airdata from the pressure measurements.

The first estimation algorithms capable of real-time operation were developed at NASA Dryden during the late 1980's for the F/A-18 High Alpha Research Vehicle (HARV) program. The HARV flight tests also demonstrated that the measurement range of FADS systems could be extended to angles of attack greater than $60^{\circ}$. The computations were performed postflight using pressure data telemetered to the ground. The estimation algorithms developed for the HARV program recently were demonstrated in a real-time flight environment on the NASA Dryden F/A-18 Systems Research Aircraft (SRA). ${ }^{10}$

For the HARV and SRA FADS systems, surface pressure measurements were related to the desired airdata parameters using a calibrated aerodynamic model. The model was derived from a combination of potential flow over a sphere ${ }^{11}$ and modified Newtonian flow theory. ${ }^{12}$ This model, which was calibrated with flight data, captured the salient features of the local flow but was simple enough to be invertable in real time. Nonlinear regression ${ }^{13}$ was used to invert the aerodynamic model. In this algorithm, all surface pressure measurements were simultaneously used to infer the airdata by linearizing the equations around the result of the previous data frame.

The nonlinear regression algorithm developed for the F/A-18 flight test programs exhibited problems with algorithm stability in the transonic and supersonic flight regimes and in the presence of undetected sensor failures. These stability problems required ad hoc software patches to artificially aid the stability by deleting failed or degraded port measurements from the estimation algorithm. These ad hoc additions to the code were computationally cumbersome and did not universally stabilize the algorithm for all flight regimes. ${ }^{10}$ The instability problems exhibited by the nonlinear regression algorithm precluded its use in a real-time feedback mode. 
To avoid problems encountered using the nonlinear regression algorithm, a new solution algorithm ${ }^{2}$ has been developed for the X-33, X-34, and X-38 demonstration vehicles. These transatmospheric vehicles generally require airdata measurements for flight-critical tasks (such as inertial guidance stabilization and inner- and outer-loop flight control) and for terminal-area energy management. This solution algorithm, superior to the nonlinear regression algorithm, has been developed by taking strategic combinations of three sensor readings to analytically decouple the angle-of-attack and angle-of-sideslip computations from the Mach number and static pressure calculations. ${ }^{2}$ This innovation allows development of an estimation algorithm whose solution speed is superior to the nonlinear regression algorithm and whose solution stability can be analytically assured for a given port arrangement.

\section{Flush Airdata Sensing Pressure Model}

As previously mentioned, the FPM is used to relate the observed surface pressures to the desired airdata state. The model is postulated as a compromise between a simple potential flow model on a sphere, ${ }^{11}$

$$
\begin{aligned}
\mathrm{C}_{\mathrm{p}}(\theta) & =\frac{p(\theta)-p_{\infty}}{q_{C}}=1-\frac{9}{4} \sin ^{2} \theta \\
& =-\frac{5}{4}+\frac{9}{4} \cos ^{2} \theta
\end{aligned}
$$

and modified Newtonian flow theory ${ }^{12}$ for blunt objects in hypersonic flow,

$$
\mathrm{C}_{\mathrm{p}}(\theta)=\frac{p_{t_{2}}-p_{\infty}}{q_{\infty}} \cos ^{2} \theta=\mathrm{C}_{\mathrm{p}_{\max }} \cos ^{2} \theta,
$$

where $C_{p}$ is the pressure coefficient at a point on the forebody surface and $\theta$ is the incidence angle between the surface normal at the pressure port and the local velocity vector. The incidence angle is geometrically related to the effective (local) angle of attack, $\alpha_{e}$, and effective (local) angle of sideslip, $\beta_{e}$, by ${ }^{10}$

$$
\begin{aligned}
\cos \left(\theta_{i}\right)= & \cos \left(\alpha_{e}\right) \cos \left(\beta_{e}\right) \cos \left(\lambda_{i}\right) \\
& +\sin \left(\beta_{e}\right) \sin \left(\phi_{i}\right) \sin \left(\lambda_{i}\right) \\
& +\sin \left(\alpha_{e}\right) \cos \left(\beta_{e}\right) \cos \left(\phi_{i}\right) \sin \left(\lambda_{i}\right)
\end{aligned}
$$

where $i$ is a port index. In equation (3), $\phi$ and $\lambda$ are the local surface coordinates referred to as the clock and cone angles, respectively. The clock angle is measured clockwise around the longitudinal axis looking aft starting from the bottom. Cone angle is the total angle the normal to the surface makes with respect to the longitudinal axis of the forebody. Figure 1 shows the clock and cone angle definitions.

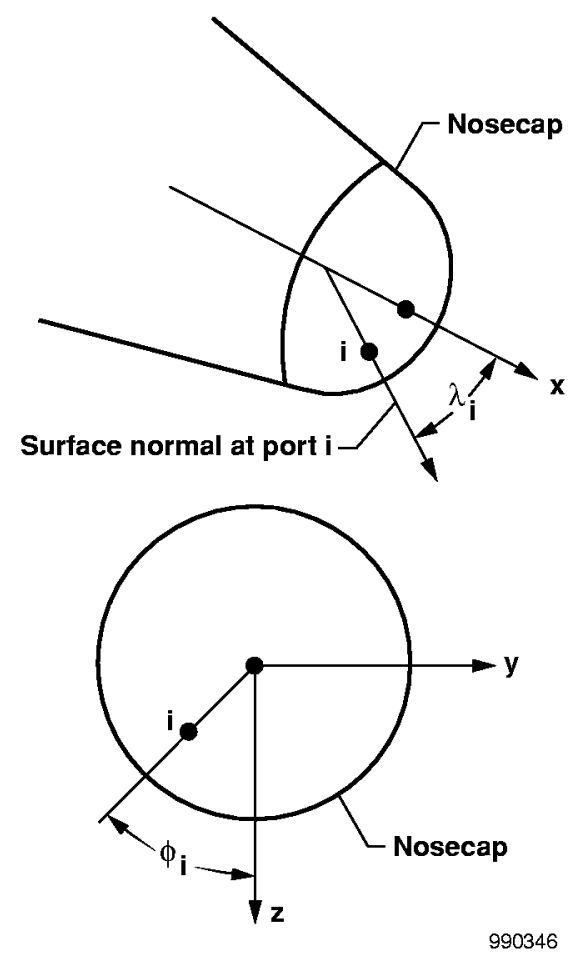

Figure 1. Clock and cone angle definitions.

The effective angles of attack and sideslip, $\alpha_{e}$ and $\beta_{e}$, are the flow direction angles as locally sensed on the blunt forebody. These angles have been deflected from the free-stream flow direction by expansion around the forebody and by upwash and sidewash induced by the rest of the vehicle. The true free-stream flow incidence angles are related to the effective angles by a set of calibrations $^{2,10}$ of the forms

$$
\delta \alpha\left[\mathrm{M}_{\infty}, \alpha_{e}\right]=\alpha_{e}-\alpha_{\text {true }}
$$

and

$$
\delta \beta\left[\mathrm{M}_{\infty}, \beta_{e}\right]=\beta_{e}-\beta_{\text {true }} .
$$

The calibrations must be empirically determined using a reference airdata set obtained either in a wind tunnel or from flight data. Fortunately, the FADS wind-tunnel calibration tests can be easily accomplished in parallel 
with traditional force and moment testing. Methods for determining these calibrations from a reference set are described in detail in the "Flush Airdata Sensing Pressure Model Calibration Procedure" section.

Equations (1) and (2) can be spliced together to give a flow model that is applicable to a large Mach number range by the parameterization

$$
\mathrm{C}_{\mathrm{p}}(\theta)=\mathrm{X}\left(\mathrm{M}_{\infty}, \alpha_{e}, \beta_{e}\right)+\mathrm{Y}\left(\mathrm{M}_{\infty}, \alpha_{e}, \beta_{e}\right) \cos ^{2} \theta
$$

where the coefficients $\mathrm{X}$ and $\mathrm{Y}$ are a function of Mach number and the effective flow angles. At $0^{\circ}$ incidence angle, equation (6) must satisfy subsonic flow conditions:

$$
\mathrm{C}_{\mathrm{p}}(0)=\frac{p_{t_{\infty}}-p_{\infty}}{q_{\infty}}=\frac{q_{c}}{q_{\infty}}
$$

or supersonic flow conditions:

$$
\mathrm{C}_{\mathrm{p}}(0)=\frac{p_{t_{2}}-p_{\infty}}{q_{\infty}}=\frac{q_{C}}{q_{\infty}}
$$

By setting

$$
\mathrm{X}\left(\mathrm{M}_{\infty}, \alpha_{e}, \beta_{e}\right)=\frac{q_{c}}{q_{\infty}} \varepsilon\left(\mathrm{M}_{\infty}, \alpha_{e}, \beta_{e}\right)
$$

and

$$
\mathrm{Y}\left(\mathrm{M}_{\infty}, \alpha_{e}, \beta_{e}\right)=\frac{q_{c}}{q_{\infty}}\left[1-\varepsilon\left(\mathrm{M}_{\infty}, \alpha_{e}, \beta_{e}\right)\right]
$$

the constraints of equation (7) are satisfied for all Mach numbers and the general FPM results:

$$
\begin{aligned}
& p(\theta)= \\
& \begin{array}{l}
q_{C}\left[\cos ^{2} \theta\left(\alpha_{e}, \beta_{e}\right)+\varepsilon\left(\mathrm{M}_{\infty}, \alpha_{e}, \beta_{e}\right) \sin ^{2} \theta\left(\alpha_{e}, \beta_{e}\right)\right] \\
\quad+p_{\infty} .
\end{array}
\end{aligned}
$$

In equations $(7)-(10), q_{\infty}$ is the free-stream dynamic pressure and $q_{C}$ is the impact pressure.

\section{Flush Airdata Sensing Solution Algorithm}

Equation (10) states that the local surface pressure at any point on a spherical (blunt) forebody is a function of the free-stream flight conditions, the angle between the effective flow vector and the surface normal, and a calibration parameter, $\varepsilon$. Because flow incidence angles $\alpha_{e}$ and $\beta_{e}$ are imbedded in $\theta$ and $\varepsilon$, equation (10) is inherently nonlinear. Usually five or more pressure measurements are used to solve for the minimum airdata state $\left(q_{C}, p_{\infty}, \boldsymbol{\alpha}, \boldsymbol{\beta}\right),{ }^{2,10}$ although the airdata can be calculated with as few as four. The minimum airdata state is sufficient to calculate all other important airdata parameters (pressure altitude, Mach number, equivalent airspeed, and so forth) except true airspeed, which requires a measurement or estimate of the free-stream temperature in order to calculate the speed of sound.

As was mentioned in the Introduction, the nonlinear regression algorithm that was applied in references 3 and 10 had problems with algorithm stability. A preferable method for estimating the airdata parameters is described in the following subsections. A detailed derivation and stability analysis has been published. ${ }^{2}$

The "Triples" Algorithm

By taking strategic combinations of three surface sensor readings ("triples"), $q_{c}, p_{\infty}$, and $\varepsilon$ are eliminated from equation (10). The resulting equation is

$$
\begin{aligned}
& \frac{p_{i}-p_{j}}{p_{j}-p_{k}} \\
& =\frac{q_{c}\left\{\cos ^{2} \theta_{i}+\varepsilon \sin ^{2} \theta_{i}\right\}+p_{\infty}-\left[q_{c}\left\{\cos ^{2} \theta_{j}+\varepsilon \sin ^{2} \theta_{j}\right\}+p_{\infty}\right]}{q_{c}\left\{\cos ^{2} \theta_{j}+\varepsilon \sin ^{2} \theta_{j}\right\}+p_{\infty}-\left[q_{c}\left\{\cos ^{2} \theta_{k}+\varepsilon \sin ^{2} \theta_{k}\right\}+p_{\infty}\right]} \\
& =\frac{\left\{(1-\varepsilon) \cos ^{2} \theta_{i}+\varepsilon\right\}-\left\{(1-\varepsilon) \cos ^{2} \theta_{j}+\varepsilon\right\}}{\left\{(1-\varepsilon) \cos ^{2} \theta_{j}+\varepsilon\right\}-\left\{(1-\varepsilon) \cos ^{2} \theta_{k}+\varepsilon\right\}} \\
& =\frac{\cos ^{2} \theta_{i}-\cos ^{2} \theta_{j}}{\cos ^{2} \theta_{j}-\cos ^{2} \theta_{k}} .
\end{aligned}
$$

Rearranging equation (11(a)) yields

$$
\Gamma_{i k} \cos ^{2} \theta_{j}+\Gamma_{j i} \cos ^{2} \theta_{k}+\Gamma_{k j} \cos ^{2} \theta_{i}=0
$$

where

$$
\begin{aligned}
\Gamma_{i k} & =\left(p_{i}-p_{k}\right) ; \\
\Gamma_{j i} & =\left(p_{j}-p_{i}\right) ; \\
\Gamma_{k j} & =\left(p_{k}-p_{j}\right) ;
\end{aligned}
$$

and $p_{i}, p_{j}$, and $p_{k}$ are the pressures used in the data "triple." Although equation (11(a)) is still nonlinear, $\varepsilon$ has been removed, thus decoupling the local flow angles from the calibration parameter. 


\section{Angle-of-Attack Estimator}

The effective angle of attack, $\alpha_{e}$, can be further decoupled from $\beta_{e}$ by using only pressures aligned along a vertical meridian (where $\phi=0^{\circ}$ or $180^{\circ}$ ). In this geometry arrangement, terms related to $\beta_{e}$ are eliminated from equation (11(b)). The result is a quadratic expression in $\tan \left(\alpha_{e}\right)$ of the form

$$
\begin{aligned}
& {\left[\Gamma_{i k} \sin ^{2} \lambda_{j}+\Gamma_{j i} \sin ^{2} \lambda_{k}+\Gamma_{k j} \sin ^{2} \lambda_{i}\right] \tan ^{2} \alpha_{e}} \\
& \quad+2\left[\Gamma_{i k} \cos \lambda_{j} \sin \lambda_{j} \cos \phi_{j}+\Gamma_{j i} \cos \lambda_{k} \sin \lambda_{k} \cos \phi_{k}\right. \\
& \left.\quad+\Gamma_{k j} \cos \lambda_{i} \sin \lambda_{i} \cos \phi_{i}\right] \tan \alpha_{e} \\
& \quad+\left[\Gamma_{i k} \cos ^{2} \lambda_{j}+\Gamma_{j i} \cos ^{2} \lambda_{k}+\Gamma_{k j} \cos ^{2} \lambda_{i}\right]=0
\end{aligned}
$$

As reference 2 shows, this quadratic equation can be reduced to the following mutually exclusive solutions:

$$
\begin{gathered}
\text { for }\left|\alpha_{e}\right| \leq 45^{\circ}, \alpha_{e}=\frac{1}{2} \tan ^{-1}\left[\frac{\mathrm{A}}{\mathrm{B}}\right], \\
\text { for }\left|\alpha_{e}\right|>45^{\circ}, \alpha_{e}=\frac{1}{2}\left(\pi-\tan ^{-1}\left[\frac{\mathrm{A}}{\mathrm{B}}\right]\right),
\end{gathered}
$$

where the parameters A and B are defined as follows:

$$
\begin{aligned}
\mathrm{A}= & \Gamma_{i k} \sin ^{2} \lambda_{j}+\Gamma_{j i} \sin ^{2} \lambda_{k}+\Gamma_{k j} \sin ^{2} \lambda_{i} \\
\mathrm{~B}= & \Gamma_{i k} \cos \phi_{j} \sin \lambda_{j} \cos \lambda_{j}+\Gamma_{j i} \cos \phi_{k} \sin \lambda_{k} \cos \lambda_{k}(14) \\
& +\Gamma_{k j} \cos \phi_{i} \sin \lambda_{i} \cos \lambda_{i} .
\end{aligned}
$$

\section{Angle-of-Sideslip Estimator}

When the effective angle of attack has been estimated, then the effective angle of sideslip may be evaluated using any combinations of the available ports except the set where all three ports lie on the vertical meridian. The result is a quadratic equation in $\tan \beta_{e}$,

$$
\mathrm{A}^{\prime} \tan ^{2} \beta_{e}+2 \mathrm{~B}^{\prime} \tan \beta_{e}+\mathrm{C}^{\prime}=0
$$

where

$$
\begin{aligned}
& \mathrm{A}^{\prime}=\left\{\Gamma_{i k} \mathrm{~b}_{j}^{2}+\Gamma_{j i} \mathrm{~b}_{k}^{2}+\Gamma_{k j} \mathrm{~b}_{i}^{2}\right\} ; \\
& \mathrm{B}^{\prime}=\left\{\Gamma_{i k} \mathrm{a}_{j} \mathrm{~b}_{j}+\Gamma_{j i} \mathrm{a}_{k} \mathrm{~b}_{k}+\Gamma_{k j} \mathrm{a}_{i} \mathrm{~b}_{i}\right\} ; \\
& \mathrm{C}^{\prime}=\left\{\Gamma_{i k} \mathrm{a}_{j}^{2}+\Gamma_{j i} \mathrm{a}_{k}^{2}+\Gamma_{k j} \mathrm{a}_{i}^{2}\right\} ;
\end{aligned}
$$

and

$$
\begin{aligned}
& \mathbf{a}_{\{i j k\}}=\cos \alpha_{e} \cos \lambda_{\{i j k\}}+\sin \alpha_{e} \sin \lambda_{\{i j k\}} \cos \phi_{\{i j k\}} \\
& \mathbf{b}_{\{i j k\}}=\sin \lambda_{\{i j k\}} \sin \phi_{\{i j k\}} .
\end{aligned}
$$

Equation (15) has two solutions; however, unlike the solution for angle of attack, these solutions are not necessarily mutually exclusive. In general, selection of the correct root depends upon the port arrangement used to determine the angle of sideslip. For most practical arrangements, however, selection of the root of equation (15) whose magnitude is closest to zero will give the correct result. Reference 2 provides a detailed discussion of the sideslip root selection criteria.

\section{Mach Number, Static Pressure, and Impact Pressure Estimator}

When the values of $\alpha_{e}$ and $\beta_{e}$ have been determined, the incidence angles at all of the ports can be evaluated, and only $\varepsilon, p_{\infty}$, and $q_{C}$ remain unknown in the pressure model (eq. (10)). As described earlier, $\varepsilon$ typically is a function of Mach number, and hence is implicitly related to both $p_{\infty}$ and $q_{C}$. As a result, solutions for $p_{\infty}$ and $q_{C}$ must be iteratively extracted at each time step. The resulting estimator ${ }^{2}$ takes the form

$$
\left[\begin{array}{c}
\hat{q}_{C} \\
\hat{p}_{\infty}
\end{array}\right]^{(m+1)}=\left\{\left[\mathbf{M}^{(m)^{\mathrm{T}}} \mathrm{Q} \mathrm{M}^{(m)}\right]^{-1} \mathbf{M}^{(m)^{\mathrm{T}}} \mathrm{Q}\right\}\left[\begin{array}{c}
p_{1} \\
p_{2} \\
\cdot \\
\cdot \\
\cdot \\
p_{n}
\end{array}\right],
$$




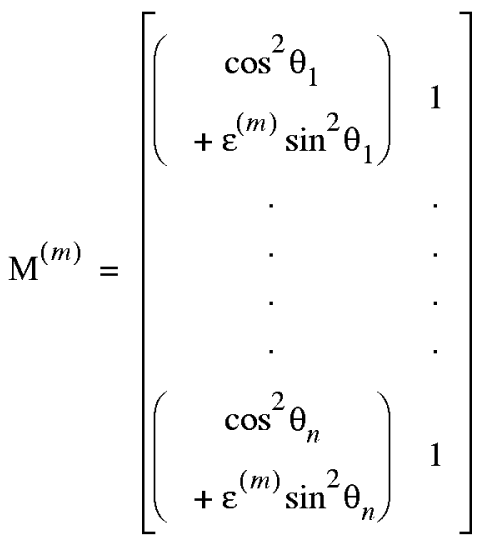

$$
\begin{aligned}
& \mathrm{Q}=\left[\begin{array}{ccccc}
\mathrm{q}_{1} & 0 & 0 & \ldots & 0 \\
0 & \mathrm{q}_{2} & 0 & \ldots & 0 \\
0 & 0 & \mathrm{q}_{3} & \ldots & 0 \\
\cdot & . & . & \ldots & . \\
. & . & . & \ldots & . \\
. & . & . & \ldots & . \\
0 & 0 & 0 & \ldots & \mathrm{q}_{n}
\end{array}\right] .
\end{aligned}
$$

In equation (16), the superscript $(m)$ refers to the result of the $m^{\text {th }}$ iteration and $n$ indicates the number of ports. For the first iteration, the value of $\varepsilon^{(m)}$ is set based on the final Mach number from the previous time step. The $\mathrm{q}_{i}$ terms are weights that have a nominal value of 1.0. Setting the value of $q_{i}$ to 0 weights the $i^{\text {th }}$ pressure reading out of the algorithm. Reference 2 provides a detailed derivation of equation (16).

When equation (16) is solved for $q_{C}$ and $p_{\infty}$, Mach number can be computed using normal one-dimensional fluid mechanics relationships. For subsonic conditions, Mach number can be directly calculated using isentropic flow laws in which, assuming that the ratio of specific heats $(\gamma)$ is 1.4 ,

$$
\frac{q_{C}}{p_{\infty}}=\left[1.0+0.2 \mathrm{M}^{2}\right]^{3.5}-1 .
$$

For supersonic conditions, the solution is computed using normal-shock wave relationships. ${ }^{14}$ For $\gamma=1.4$,

$$
\frac{q_{C}}{p_{\infty}}=166.92 \mathrm{M}_{\infty}^{2}\left[\frac{\mathrm{M}_{\infty}^{2}}{7 \mathrm{M}_{\infty}^{2}-1}\right]^{2.5}-1
$$

Equation (18) is easily solved using a Taylor's series expansion and a reversion of series to compute Mach number: ${ }^{15}$

$$
\mathrm{M}_{\infty}=\frac{\sqrt{\sum_{i=0}^{9} \mathrm{r}_{i}\left(\mathrm{~W}^{i}\right)}}{\mathrm{W}} ; \mathrm{W}=1.839371\left(\frac{p_{\infty}}{p_{t}}\right),
$$

where the coefficients of the summation are $r=[1.42857$, $-0.357143,-0.0625,-0.025,-0.012617,-0.00715$, $-0.0043458,0,0,-0.0087725]$.

For hypersonic Mach numbers, a very significant temperature rise (greater than $1000^{\circ} \mathrm{F}$ ) occurs across the bow shock wave and the ratio of specific heats can no longer be assumed to be constant. Therefore, some error is expected using equation (18) in the Mach number calculation. Fortunately, because pressure depends primarily upon the mechanical aspects of the flow, influences caused by high-temperature gas properties are secondary. Numerical analyses of equation (18) have shown that the error introduced is less than 0.2 percent for Mach numbers less than 4.0. ${ }^{16}$ This error is considered acceptable for real-time applications for most aerospace vehicle designs.

\section{Flush Airdata Sensing Pressure Model Calibration Procedure}

The FPM described by equations (3) and (10) has three parameters that must be determined by empirical calibrations: $\delta \alpha, \delta \beta$, and $\varepsilon$. These calibrations allow the FPM to be "shaped" to characterize pressure distributions and flow deflections for various forebody shapes. Given a set of reference conditions (obtained from wind-tunnel or flight data) that includes the surface pressure distribution, the true angles of attack and sideslip, the free-stream Mach number, and dynamic or static pressure, the model parameters may be estimated using the following algorithm:

1. Equations (13) and (15) are used to estimate $\alpha_{e}$ and $\beta_{e}$ from the surface pressure distribution. The flow angle calibrations are then given by equations (4) and (5).

2. Given $\alpha_{e}$ and $\beta_{e}$, the surface incidence angles are evaluated for each of the pressure ports using equation (3). 
3. The result of step 2 is substituted into equation (10) and rearranged:

$\mathrm{C}_{\mathrm{p}_{\mathrm{c}}}(\theta)-\cos ^{2} \theta=\sin ^{2} \theta \cdot \varepsilon\left(\mathrm{M}_{\infty}, \alpha_{e}, \beta_{e}\right)$,

where

$$
\mathrm{C}_{\mathrm{p}_{\mathrm{c}}}(\theta)=\frac{p(\theta)-p_{\infty}}{q_{C}}
$$

4. Equation (20) is evaluated and collecting for all of the $n$ pressure ports yields

$$
\left[\begin{array}{c}
\mathrm{C}_{\mathrm{p}_{\mathrm{c}}}\left(\theta_{1}\right)-\cos ^{2} \theta_{1} \\
\cdot \\
\cdot \\
\mathrm{C}_{\mathrm{p}_{\mathrm{c}}}\left(\theta_{n}\right)-\cos ^{2} \theta_{n}
\end{array}\right]=\left[\begin{array}{c}
\sin ^{2} \theta_{1} \\
\cdot \\
\cdot \\
\cdot \\
\sin ^{2} \theta_{n}
\end{array}\right] \cdot \varepsilon\left(\mathrm{M}_{\infty}, \alpha_{e}, \beta_{e}\right) .
$$

5. Equation (21) can be directly solved ${ }^{17}$ to give a least-squares estimate of $\varepsilon$ :

$$
\varepsilon\left(\mathrm{M}_{\infty}, \alpha_{e}, \beta_{e}\right)=\frac{\sum_{i=1}^{n} \sin ^{2} \theta_{i}\left[\mathrm{C}_{\mathrm{p}_{\mathrm{c}}}\left(\theta_{i}\right)-\cos ^{2} \theta_{i}\right]}{\sum_{i=1}^{n} \sin ^{4} \theta_{i}} .
$$

6. The estimate of $\varepsilon$ derived from equation (22) gives the minimum fit error with respect to the pressure distribution. The estimate, however, may not give the minimum error with respect to the reference Mach number. If a refinement is desired to minimize the fit error with respect to Mach number, then a "steepest-descent" algorithm" ${ }^{18}$ can be used. For $M_{\text {ref }}-M^{(j)}>\delta M_{\text {required }}$,

$$
\varepsilon^{(m+1)}=\varepsilon^{(m)}+\frac{\partial \varepsilon^{(m)}}{\partial \mathrm{M}}\left[\mathrm{M}_{\mathrm{ref}}-\mathrm{M}^{(m)}\right]
$$

In equation $(23),\left(\partial \varepsilon^{(m)}\right) / \partial \mathrm{M}$ is the sensitivity derivative of the calibration parameter with respect to Mach number, and $\mathrm{M}^{(m)}$ is the Mach number solution at the $m^{\text {th }}$ iteration. The derivative $\left(\partial \varepsilon^{(m)}\right) / \partial \mathrm{M}$ is numerically determined by perturbing Mach number and determining the change in $\varepsilon^{(m)}$.
Using the above procedures, the model calibrations for a new configuration can be systematically developed from the reference data. Typically, systematic trends in the calibration parameters are identified by plotting the estimated calibration parameters as a function of reference variables and visually inspecting the results. Care should be taken to ensure that adequate reference data are generated in order to cover the desired flight envelope. Also, calibrations with respect to different geometrical configurations for the vehicle (for example, gear up or down and control surface deflections) may be required. Detailed calibration examples for various forebody shapes are given in the "Results" section.

\section{Blunt-Body Pressure Data Sources}

Three calibration parameters must be evaluated for any FADS system: the shape and compressibility parameter, $\varepsilon$; the angle-of-attack flow correction angle, $\delta \alpha$; and the angle-of-sideslip flow correction angle, $\delta \beta$. As mentioned in the introduction, a general set of guidelines regarding the structure of the calibration curves for various FADS systems has never been developed and reported. This paper attempts to develop such a set of rules by deriving calibrations for a variety of shapes. The calibrations are derived from three distinct data sources: analytical solutions for simple geometries, wind-tunnel data, and flight data. The following subsections detail the geometrical configurations analyzed and the data sources. Results obtained by applying the FADS calibration procedures to the data are presented in the "Results" section.

\section{Analytical Solutions for Simple Geometries}

To better understand the variations in the FADS calibration caused by configuration changes, an evaluation of exact, analytical solutions was desired. Two fixed-geometry incompressible solutions already exist that exactly fit into the FPM. Incompressible, uniform crossflow over a cylinder has a pressure solution given by:

$$
\begin{aligned}
C_{p}(\theta) & =\frac{p(\theta)-p_{\infty}}{q_{C}}=1-4 \sin ^{2} \theta \\
& =\cos ^{2} \theta-3 \sin ^{2} \theta
\end{aligned}
$$

Incompressible, uniform flow over a sphere has a pressure distribution described by: 


$$
\begin{aligned}
\mathrm{C}_{\mathrm{p}}(\theta) & =\frac{p(\theta)-p_{\infty}}{q_{C}}=1-\frac{9}{4} \sin ^{2} \theta \\
& =\cos ^{2} \theta-\frac{5}{4} \sin ^{2} \theta
\end{aligned}
$$

The FPM (eq. (10)), in which $\varepsilon$ is equal to -3 for a cylinder and -1.25 for a sphere, exactly models the incompressible flow solutions.

A general, analytical, potential-flow solution algorithm $^{19}$ was developed for the three-dimensional ellipsoid shown in figure 2. This algorithm calculates the pressure coefficient at any point on the surface of the ellipsoid, and the ellipsoid can be arbitrarily inclined to the free stream. The ellipsoid fineness ratio, $\mathrm{f}$, is defined as the ratio of the major to the minor ellipsoid axes; the

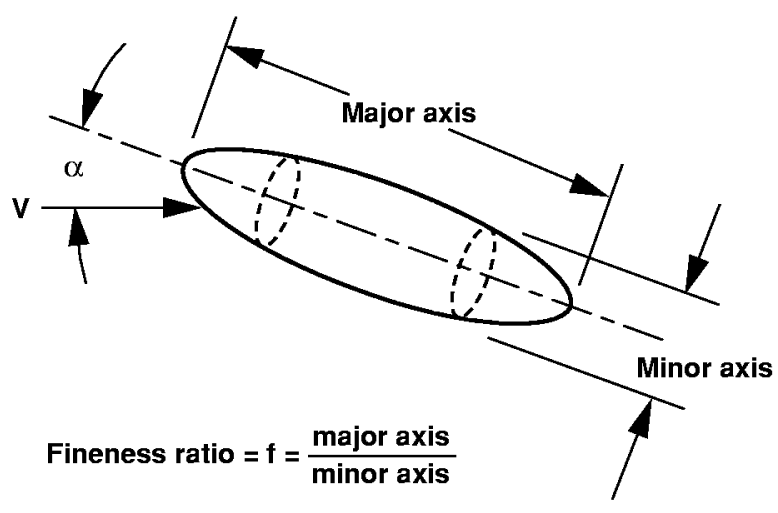

990227

Figure 2. Ellipsoid configuration. major axis is also the reference axis. Analysis must be limited to conditions where flow separation is not expected because the incompressible solution will not predict it.

Because the FPM was adapted from a spherical model, the ellipsoid provides a strenuous test of the FPM application to nonspherical shapes. This test is necessary if the FPM is to be generally applicable. The analytical ellipsoid pressure model allows the evaluation of the FADS calibration parameters with varying forebody shape, angle of attack, and angle of sideslip.

\section{Wind-Tunnel Data}

The potential flow solutions described in the previous section clearly do not include the effects of viscosity, Reynolds number, or compressibility. To understand these effects in greater detail, data from a series of windtunnel tests were analyzed. These data cover a wide range of Mach numbers, incidence angles, and forebody shapes. The wind-tunnel data also were used to demonstrate the sensitivity of the FADS calibration to the port locations. The test facilities, model shapes, test conditions, and wind-tunnel instrumentation are described in detail in the following subsections. Table 1 shows the range of test conditions analyzed for each of the wind-tunnel models.

\section{Forebody Wind-Tunnel Tests}

A series of wind-tunnel tests, designed to test the adaptability of the FPM and the accompanying calibration procedures, was conducted in the National Technical Systems (Saugus, California) $4 \mathrm{ft}-\mathrm{by}-4 \mathrm{ft}$

\begin{tabular}{|c|c|c|c|c|c|c|c|}
\hline \multirow[b]{2}{*}{ Configuration } & \multirow[b]{2}{*}{ Tunnel } & \multicolumn{2}{|c|}{ Mach number range } & \multicolumn{2}{|c|}{$\begin{array}{c}\alpha \text { range, } \\
\text { deg }\end{array}$} & \multicolumn{2}{|c|}{$\begin{array}{c}\beta \text { range, } \\
\text { deg }\end{array}$} \\
\hline & & Low & High & Low & High & Low & High \\
\hline 8-deg cone & NTS & 0.30 & 4.50 & -5 & 30 & 0 & 0 \\
\hline $\begin{array}{c}\mathrm{X}-33 \\
\text { forebody }\end{array}$ & NTS & 0.30 & 4.50 & -5 & 30 & -5 & 15 \\
\hline $\begin{array}{l}\text { Rankine } \\
\text { half-body }\end{array}$ & NTS & 0.30 & 4.50 & -5 & 30 & 0 & 0 \\
\hline$X-33$ & 16-Foot & 0.25 & 1.20 & -10 & 24 & -10 & 16 \\
\hline$X-33$ & UPWT & 1.60 & 4.50 & -10 & 24 & -10 & 10 \\
\hline$X-34$ & 14- by 22 -Foot & 0.30 & 0.30 & -4 & 20 & -8 & 8 \\
\hline $\mathrm{X}-38$ & LMVS & 0.40 & 0.95 & -5 & 24 & -4 & 4 \\
\hline
\end{tabular}

Table 1. Wind-tunnel model test conditions. 
blow-down-to-atmosphere wind tunnel. The facility operates at Mach numbers ranging from 0.25 to 5.00 . High-pressure air is fed through a variable-geometry nozzle to achieve the desired test conditions. The walls, floor, and ceiling in the transonic test section are 22-percent porous to minimize reflected shock waves.

This series of wind-tunnel tests was conducted with three models (fig. 3). The first model was a spherically blunted 8-deg nosecone. This shape is similar to several single-stage-to-orbit launch vehicle designs and fighter forebody shapes. The second model shape was achieved by rotating a two-dimensional Rankine half-body ${ }^{* * *}$ along its central axis. The result was an ellipse-like forebody that approaches a cylindrical shape at infinite distance. The third shape accurately modeled the first 20 percent of body length of the X-33 single-stage-toorbit vehicle (Lockheed Martin Skunk Works, Palmdale, California) at a scale of approximately 4.2 percent. A smooth boat-tail afterbody was added to the X-33 forebody to move the base separation away from the nosecap region. This model represents nonaxisymmetric, lifting-body type configurations.

Each of the models consisted of three parts: the nosecap, the body, and a common mounting adapter. The nosecap was made of stainless steel to minimize any damage during the wind-tunnel blows. Figure 4

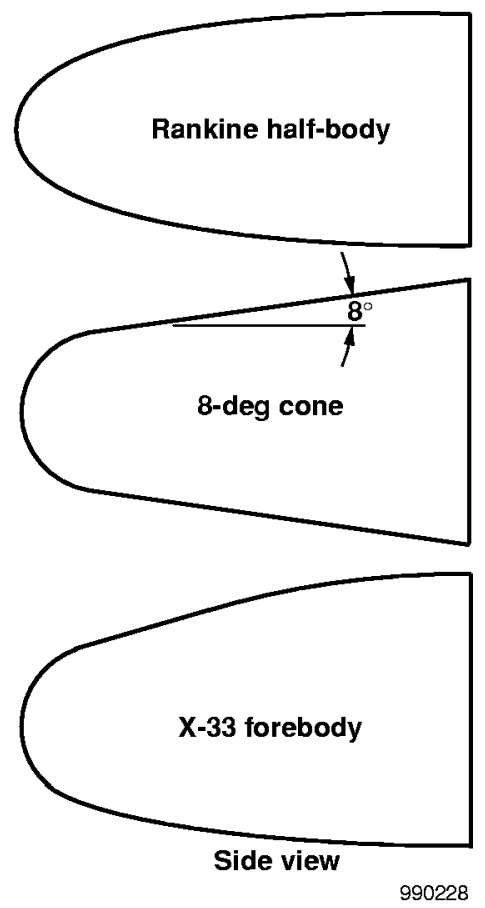

Figure 3. Wind tunnel-test shapes.

\footnotetext{
*** The Rankine half-body comes from the inviscid, incompressible solution for a point source in uniform flow.
}

shows the port layout and numbering system for the nosecap. Each of the FADS pressure ports were located and drilled normal to the surface. Stainless steel tubing (0.031 in. inside diameter) connected the external model surface to the rubber tubing that was plumbed to the pressure transducer. The model bodies were made of aluminum. A stainless-steel mounting adapter served as the structure that held the nosecap and body, mounted the completed model to the wind-tunnel sting, and housed the model instrumentation.

Two types of instrumentation were mounted in the model adapter. First, a 32-port electronic scanning pressure (ESP) module (Pressure Systems Incorporated, Hampton, Virginia) was located close to the nosecap to measure differential pressure $\left( \pm 15 \mathrm{lbf} / \mathrm{in}^{2}\right)$ between the nose ports and atmospheric pressure. The second internal instrumentation was a digital inclinometer, used for measuring the model incidence angle during the wind-tunnel runs. Because no balance was used in the test, the inclinometer was used to account for sting bending under loaded conditions. When the model was upright, the inclinometer measured angle of attack; when the model was rolled $90^{\circ}$, the inclinometer was reinstalled to measure angle of sideslip.

\section{$\underline{X-33 \text { Wind-Tunnel Tests }}$}

FADS wind-tunnel calibration data were obtained for a 2-percent model of the X-33 vehicle (designation $604 \mathrm{~B} 002 \mathrm{C}$ ) in the 16-Foot Transonic Tunnel ${ }^{20}$ and the Unitary Plan Wind Tunnel at NASA Langley. The 16-Foot Transonic Tunnel is a closed-circuit, singlereturn, continuous-flow, atmospheric tunnel that

\begin{tabular}{|c|c|c|}
\hline Port & $\lambda$, deg & $\phi$, deg \\
\hline 1 & 0 & 0 \\
\hline 2 & 20 & 0 \\
\hline 3 & 20 & 90 \\
\hline 4 & 20 & 180 \\
\hline 5 & 20 & 270 \\
\hline 6 & 30 & 0 \\
\hline 7 & 30 & 90 \\
\hline 8 & 30 & 180 \\
\hline 9 & 30 & 270 \\
\hline 10 & 45 & 0 \\
\hline 11 & 45 & 90 \\
\hline 12 & 45 & 180 \\
\hline 13 & 45 & 270 \\
\hline 14 & 60 & 0 \\
\hline 15 & 60 & 90 \\
\hline 16 & 60 & 180 \\
\hline 17 & 60 & 270 \\
\hline
\end{tabular}

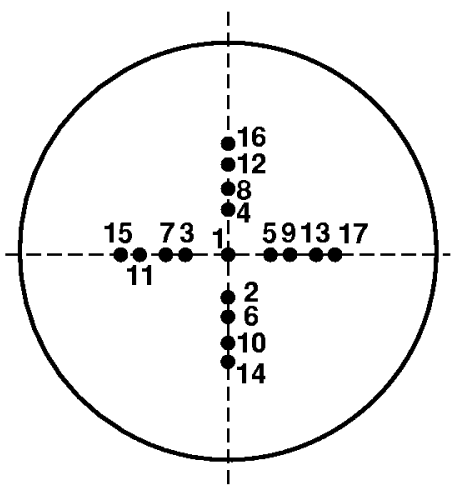

Figure 4. Port arrangement of wind tunnel-test models. 
operates at Mach numbers ranging from 0.2 to 1.3. The tunnel has an octagonal, 16-ft slotted test section. Some run limitations are sometimes imposed near transonic speeds because of the lack of porous walls to absorb reflected shock waves. The small size of the X-33 model, however, allowed testing at transonic Mach numbers without reflected shock-wave interference. The Unitary Plan Wind Tunnel is a closed-circuit, continuous-flow, variable-density, supersonic wind tunnel with two $4 \mathrm{ft}-\mathrm{by}-4 \mathrm{ft}$ test sections. One test section operates at a Mach number range from 1.5 to 2.9, and the other operates at a range from Mach 2.3 to approximately Mach 4.5. The Reynolds number was nearly constant at $2 \times 10 \% \mathrm{ft}$. Results of the X-33 FADS wind-tunnel tests were also previously reported. ${ }^{2}$

The 2-percent X-33 model was built to measure total vehicle forces and moments and nosecap surface pressures. The wind-tunnel model was machined from a solid piece of aluminum, and the nosecone was made of stainless steel to minimize damage from tunnel contaminants. Tests were conducted with and without a grit ring installed aft of the FADS ports, but little variation existed in the pressure distribution.

The nosecap surface pressures (fig. 5) were sensed using an onboard ESP module that produced a timemultiplexed analog output with 32 channels. The ESP sensor was a $\pm 10-\mathrm{lbf} / \mathrm{in}^{2}$ differential module with a manufacturer's accuracy of better than \pm 0.1 percent of full-scale reading. The time-multiplexed analog outputs from the ESP module were tagged and sampled using a 16-bit analog-to-digital conversion system. The 2-percent X-33 model FADS pressure ports were drilled normal to the surface with a diameter of $0.02 \mathrm{in}$.

\section{X-34 Wind-Tunnel Tests}

The FADS wind-tunnel calibration data were obtained for a 10-percent scale model of the X-34 vehicle (Orbital Sciences Corporation, Dulles, Virginia) in the 14- by 22 -Foot Subsonic Tunnel at NASA Langley. The 14- by 22 -Foot Subsonic Tunnel ${ }^{22}$ features a closed circuit and operates at atmospheric pressure. The X-34 tests were performed at a nominal Mach number of 0.3 and a dynamic pressure of $125 \mathrm{lbf} / \mathrm{ft}^{2}$. The free-stream angle of attack ranged from $-4^{\circ}$ to $20^{\circ}$; the angle of sideslip ranged from $-8^{\circ}$ to $8^{\circ}$.

The model was made of a carbon fiber-fiberglass composite and was sting-mounted at the base. Figure 5 shows the locations of the ports. The X-34 model FADS orifices were connected to a 32-port ESP module. The ESP sensor was a $\pm 2.5-\mathrm{lbf} / \mathrm{in}^{2}$ differential module with a

\begin{tabular}{|c|c|c|}
\hline Port & $\lambda$, deg & $\phi$, deg \\
\hline 1 & 20 & 0 \\
\hline 2 & 20 & 0 \\
\hline 3 & 20 & 90 \\
\hline 4 & 20 & 180 \\
\hline 5 & 20 & 270 \\
\hline 6 & 45 & 0 \\
\hline
\end{tabular}

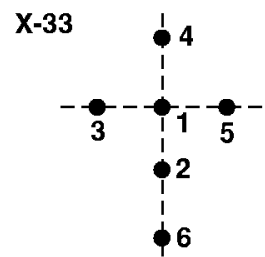

\begin{tabular}{|c|c|c|}
\hline Port & $\lambda$, deg & $\phi$, deg \\
\hline 1 & 16.1 & 0 \\
\hline 2 & 38.6 & 0 \\
\hline 3 & 61.1 & 0 \\
\hline 4 & 6.4 & 180 \\
\hline 5 & 28.9 & 180 \\
\hline 6 & 45.0 & 90 \\
\hline 7 & 45.0 & 270 \\
\hline 8 & 90.0 & 0 \\
\hline
\end{tabular}

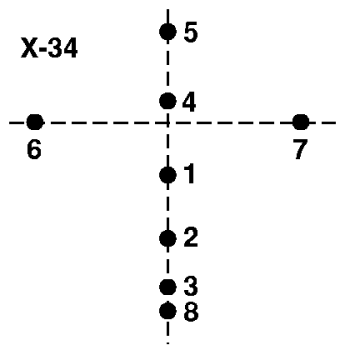

\begin{tabular}{|c|c|c|}
\hline Port & $\lambda$, deg & $\phi$, deg \\
\hline 1 & 0 & 0 \\
\hline 2 & 29.41 & 90 \\
\hline 3 & 36.12 & 180 \\
\hline 4 & 27.41 & 270 \\
\hline 5 & 32.77 & 0 \\
\hline 6 & 35.91 & 90 \\
\hline 7 & 50.34 & 180 \\
\hline 8 & 35.91 & 270 \\
\hline 9 & 54.88 & 0 \\
\hline
\end{tabular}

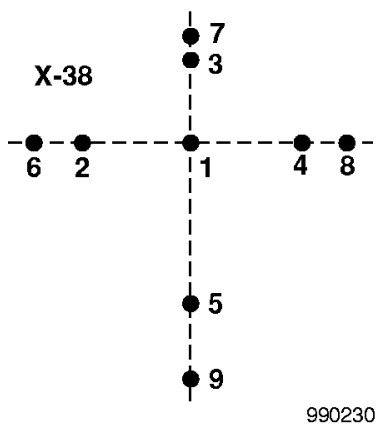

Figure 5. X-33, X-34, and X-38 port arrangements.

manufacturer's accuracy of better than \pm 0.1 percent of full-scale reading. The time-multiplexed analog outputs from the ESP module were tagged and sampled using a 16-bit analog-to-digital conversion system. The X-34 model FADS pressure ports with a diameter of $0.06 \mathrm{in}$. were drilled normal to the surface. ESP zero-shift calibrations were performed when the tunnel temperature changed by more than $4.5^{\circ} \mathrm{F}$ and after each model changeover.

\section{$\underline{\mathrm{X}-38 \text { Wind-Tunnel Tests }}$}

The $\mathrm{X}-38$ vehicle (designated V132) is similar to the $\mathrm{X}$-24A lifting-body design. The X-38 deploys and lands under a parafoil rather than on a runway. Modifications to the $\mathrm{X}-24 \mathrm{~A}$ design include removing the center fin to allow for parafoil storage, redesigning the aft structure to improve the base pressure, and replacing the booster rockets with a drogue chute. 
The nine-hole FADS system installed on the nosecap (fig. 5) was calibrated at the Lockheed Martin Vought Systems (LMVS) transonic wind tunnel in Dallas, Texas. The $4 \mathrm{ft}-\mathrm{by}-4 \mathrm{ft}$ blow-down-to-atmosphere wind tunnel operates at Mach numbers ranging from 0.25 to 5.00. High-pressure air is fed through a variablegeometry nozzle to achieve the desired test conditions. A 5.2-percent scale model was used to represent the 23-ft full-scale X-38 vehicle. The Mach range varied from 0.40 to 0.95 . The angle of attack varied from $-5^{\circ}$ to $24^{\circ}$, and the angle of sideslip varied from $-4^{\circ}$ to $4^{\circ}$.

\section{Miscellaneous Wind-Tunnel Test Data}

A search for literature containing experimental pressure distribution data on generic shapes yielded information that contributes to the goals of the current study. Data were found for a sphere; ${ }^{23}$ spherically blunted 9-deg, 12.5-deg, 18-deg, and 45-deg nosecones; ${ }^{24,25,26}$ and a spherically capped cylinder. The 12.5-deg, 18-deg, and 45-deg nosecone data were only available at hypersonic Mach numbers (greater than Mach 6), because these shapes were being considered for reentry capsule shapes. Most reentry capsule experiments were exclusively conducted at $0^{\circ}$ angle of attack.

\section{Flight Test Data}

Data obtained from two full-scale FADS flight tests are presented in the following subsections. These flight data were obtained from a real-time FADS demonstration flown on the NASA Dryden F/A-18 SRA $^{10}$ and from transonic FADS tests on an F-14 aircraft. ${ }^{8}$ The flight data results are compared with analytical and wind-tunnel analyses in the "Results" section.

\section{F/A-18 Systems Research Aircraft Flush Airdata Sensing Flight Tests}

The SRA flight tests demonstrated a prototype realtime FADS system. The test envelope included Mach numbers as high as 1.6 and angles of attack greater than $45^{\circ}$. The airdata were sensed by 11 orifices located on a composite nosecap molded into the structure of the aircraft radome and faired smooth to the surface. Figure 6 shows the locations of the pressure ports on the nosecap.

The SRA FADS pressures were sensed by 11 miniaturized, digital, absolute-pressure transducers.

\begin{tabular}{|c|c|c|}
\hline Port & $\lambda$, deg & $\phi$, deg \\
\hline 1 & 0 & 0 \\
\hline 2 & 40 & 0 \\
\hline 3 & 40 & 180 \\
\hline 4 & 55 & 0 \\
\hline 5 & 55 & 90 \\
\hline 6 & 55 & 180 \\
\hline 7 & 55 & 270 \\
\hline 8 & 60 & 45 \\
\hline 9 & 60 & 135 \\
\hline 10 & 60 & 225 \\
\hline 11 & 60 & 315 \\
\hline
\end{tabular}

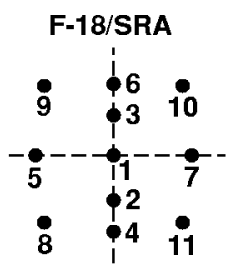

\begin{tabular}{|c|c|c|}
\hline Port & $\lambda$, deg & $\phi$, deg \\
\hline 1 & 60 & 180 \\
\hline 2 & 40 & 180 \\
\hline 3 & 20 & 180 \\
\hline 4 & 0 & 0 \\
\hline 5 & 20 & 0 \\
\hline 6 & 40 & 0 \\
\hline 7 & 60 & 0 \\
\hline 8 & 60 & 90 \\
\hline 9 & 30 & 90 \\
\hline 10 & 30 & 270 \\
\hline 11 & 60 & 270 \\
\hline
\end{tabular}

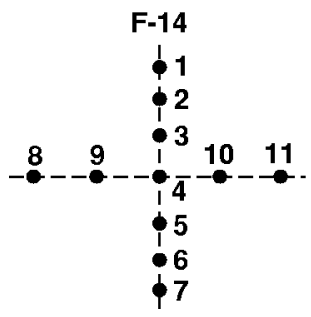

990231

Figure 6. F/A-18 SRA and F-14 port arrangements.

Each absolute-pressure transducer incorporates a fouractive-arm strain-gage bridge for data sensing; internal signal conditioning with a $20-\mathrm{Hz}$ antialiasing low-pass filter and output signal amplification; and a 20-bit analog-to-digital conversion. The transducers have a repeatability that exceeds 0.01 percent of full scale and a measurement range from 1.50 to $40.00 \mathrm{lbf} / \mathrm{in}^{2}$ atmosphere. Data collection and algorithm computations are performed onboard in real time by two commercially available single-board computers inserted in a ruggedized flight chassis. The raw pressure measurements and onboard airdata computations were telemetered to a ground station where they were recorded for postflight analyses.

The SRA FADS system was calibrated by comparing the onboard calculations with flight-derived reference airdata values and adjusting the calibration coefficients using the previously described calibration procedures. The flight reference data were generated by merging complementary information from multiple data sources, including the onboard inertial navigation system attitudes, rates, and accelerations; radar-tracking velocity and position data; and rawinsonde weather balloon data. 


\section{F-14 Flush Airdata Sensing Flight Tests}

The F-14 FADS flight tests were performed at NASA Dryden on an aircraft with special equipment modifications that were part of a program demonstration for new flight control techniques. ${ }^{27}$ The equipment modifications included a pair of deployable, canard-like surfaces on the fuselage forebody for spin recovery and a gun fairing in the left side of the fuselage forebody. Although the canards were closed for the FADS tests, they may have some effect on the upstream flow. The geometric asymmetry caused by the gun fairing may have also influenced some of the FADS pressure measurements.

For the F-14 tests, 11 flush orifices (0.031 in. diameter) were installed on a spherically blunted nosecap in a cruciform pattern. The nosecap blended with the nose of the aircraft. Orifices along the vertical axis were placed at angular increments of $20^{\circ}$; those along the horizontal axis were placed at increments of $30^{\circ}$. Additional flush-mounted orifices were installed on the nose section aft of the nosecap. These 0.125 in.diameter orifices were located in 2 rows around the fuselage: a row of 4 orifices evenly spaced $24.0 \mathrm{in}$. aft of the nose apex and another row of 12 orifices $50.0 \mathrm{in}$. aft of the nose apex. The nose-section orifices were installed to furnish a suitable static-pressure source to be used in conjunction with the orifices on the nosecap. Figure 6 shows the locations of the FADS ports. Details of the F-14 instrumentation system are reported in reference 8 .

For the F-14 FADS tests, data were obtained for Mach numbers between 0.60 and 1.60, for angles of attack to a maximum of $26.0^{\circ}$, and for angles of sideslip to a maximum of $11.0^{\circ}$. The flight Reynolds numbers varied between $1.0 \times 10^{6} \% \mathrm{ft}$ and $5.5 \times 10^{6} \% \mathrm{ft}$. High flow angles at high transonic speeds were limited.

\section{$\underline{\text { Results }}$}

The suitability of various vehicle shapes for a FADS system is discussed in this section. First, analytical solutions for the incompressible pressure field over a sphere and varying fineness-ratio ellipsoids are used to validate the suitability of the FPM and calculate the appropriate FADS calibration parameters $(\varepsilon, \delta \alpha$, and $\delta \beta)$ at incompressible flow conditions. Varying the ellipsoid fineness ratio reveals the behavior of the FPM calibration for varying forebody shape; varying the free-stream angle of attack reveals the behavior of the calibration to changes in the vehicle orientation to the free stream.
Second, using wind-tunnel and flight data, the variation in the calibrations is extended to a wide variety of blunt-forebody shapes. The effect of shape and compressibility is assessed at Mach numbers to a maximum of 5.0.

Last, the sensitivity of the FADS calibration to the port locations is addressed. The modeling suitability of the FPM is illustrated by plotting the impact pressure coefficient, $\mathrm{C}_{\mathrm{p}_{\mathrm{c}}}$, as a function of the incidence angle. The $C_{p_{c}}$ is found by rearranging the FPM (eq. (10)):

$$
\mathrm{C}_{\mathrm{p}_{\mathrm{c}}}(\theta)=\frac{p(\theta)-p_{\infty}}{q_{c}}=\cos ^{2} \theta+\varepsilon \sin ^{2} \theta \text {. }
$$

\section{Ellipsoid Analytical Data}

The ellipsoid pressure calculations provide a comprehensive data package to test the validity of the FPM. Although the data represent only incompressible flow conditions, variations in the FADS calibration caused by forebody shape and angle of attack were investigated.

\section{Validation of the Flush Airdata Sensing Pressure Model}

The ability to model the pressure distribution over the forward portion of a blunt body is essential to ensure general applicability of the FPM to a variety of vehicles. The analytical ellipsoid solution ${ }^{19}$ was used to generate forebody pressures for ellipsoids ranging from a sphere $(f=1)$ to a high-fineness-ratio ellipsoid $(f=20)$. Figure 7 shows the calculated impact-pressure coefficients and the calibrated FPM as a function of the flow incidence angle, $\theta$, for varying ellipsoid fineness ratios at $0^{\circ}$ angle of attack. In all cases, a calibration parameter, $\varepsilon$, exists that, when used in equation (10), identically matches the analytical pressure distribution. As expected (eq. (25)), the value of $\varepsilon$ for a sphere is equal to -1.25 . As the fineness ratio becomes large, the value of $\varepsilon$ approaches 0 .

As the angle of attack increases to $30^{\circ}$, no degradation in the pressure modeling capability of the FPM is found. Figure 8 shows that the least-squares estimate of $\varepsilon$ results in a perfect match of the data. Note that the calibration for the sphere is unchanged with increasing angle of attack; however, the nonspherical shapes exhibit a reduced sensitivity of the calibration to fineness ratio at angles of attack greater than $10^{\circ}$. 


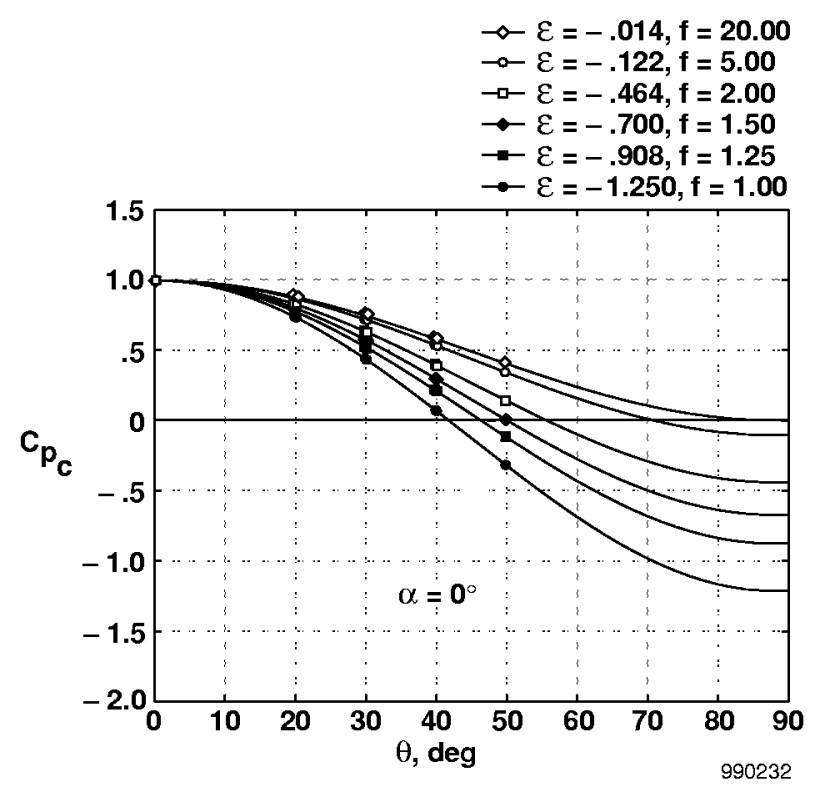

Figure 7. Comparison of the FPM and the analytical impact-pressure coefficient as a function of flow incidence angle, ellipsoid, $\alpha=0^{\circ}$.

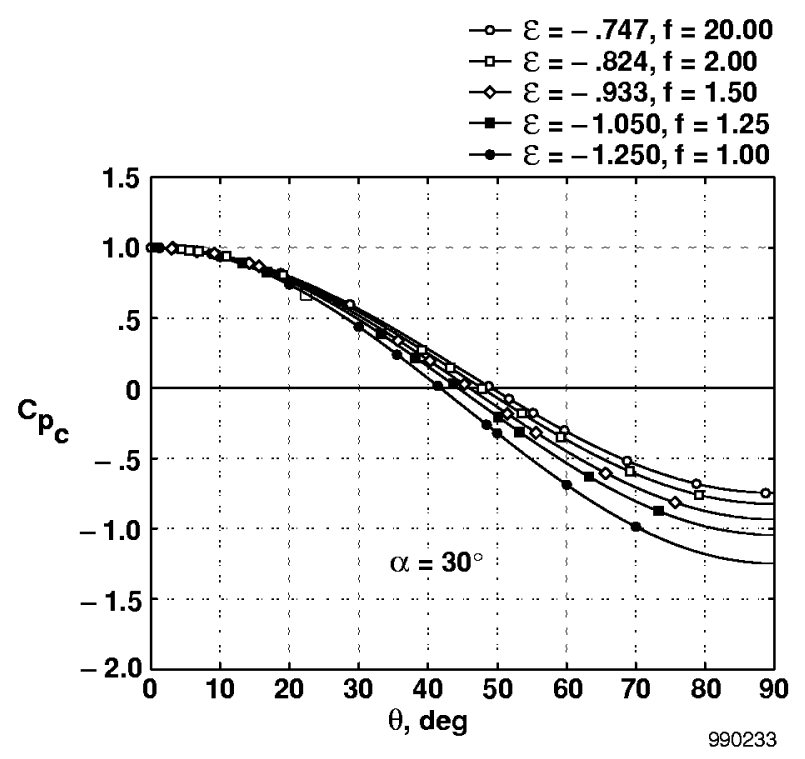

Figure 8. Comparison of the FPM and the analytical impact-pressure coefficient as a function of flow incidence angle, ellipsoid, $\alpha=30^{\circ}$.

\section{Calibration of the Shape and Compressibility Parameter}

Because the FADS solution algorithm computes effective angles of attack and sideslip first, the $\varepsilon$ variation caused by angle of attack should be documented as a function of effective angle of attack rather than true angle of attack. This method also reduces the nonlinearity in the calibration model.

Figure 9 shows a plot of $\varepsilon$ as a function of effective angle of attack for varying fineness-ratio ellipsoids. The plot confirms that $\varepsilon$ is equal to -1.25 for a sphere $(\mathrm{f}=1)$. Because the flow field of the sphere is independent of orientation, $\varepsilon$ does not vary with changes in angle of attack. For small increases in the fineness ratio (for example, $\mathrm{f}=1.25$ ), $\varepsilon$ significantly increases and the dependence of $\varepsilon$ on the effective angle of attack becomes noticeable. Increasing fineness ratio results in greater concavity of the $\varepsilon$-as-a-function-of- $\alpha_{e}$ curve. As the fineness ratio of the ellipsoid increases, causing its shape to approach a slender rod, the value of $\varepsilon$ approaches 0 at $0^{\circ}$ angle of attack.

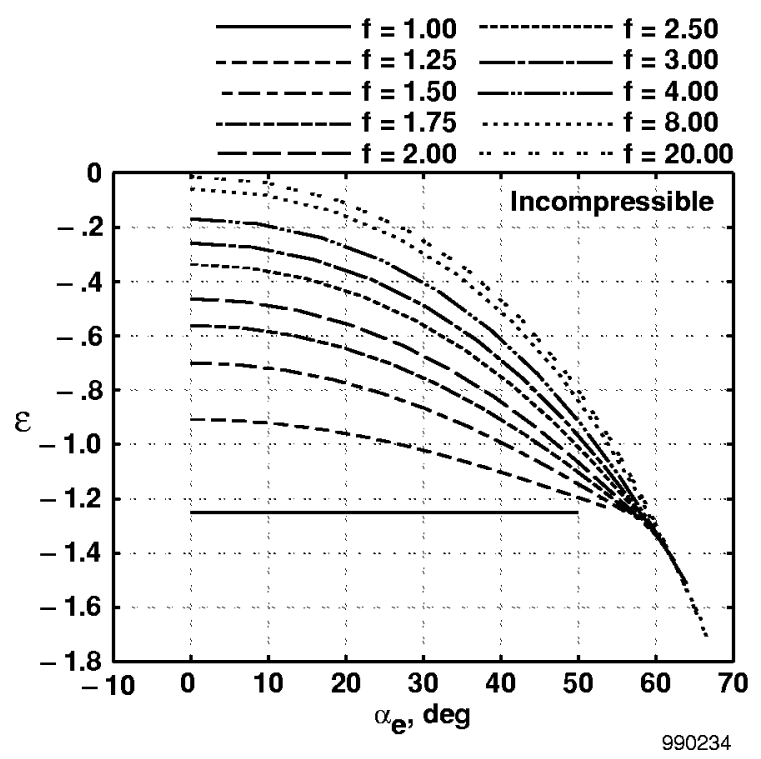

Figure 9. FPM calibration variation with effective angle of attack for varying fineness-ratio ellipsoids.

Evaluating the FPM (eq. (10)) for $\varepsilon=0$ at $\lambda=0^{\circ}$ and $\lambda=90^{\circ}$ yields total and static pressure, respectively. These results match the expected measurements of total pressure at the tip $\left(\lambda=0^{\circ}\right)$ and 
static pressure along the side $\left(\lambda=90^{\circ}\right)$ of a thin rod in subsonic flow. The shape of the $\varepsilon=\varepsilon\left(\alpha_{e}\right)$ curve can be approximated by a polynomial equation, allowing simple calibration storage in a real-time airdata system.

\section{Calibration of the Upwash Correction}

Equation (4) requires an upwash correction, $\delta \alpha$, to compute true angle of attack from effective angle of attack. Figure 10 shows a plot of the upwash correction for varying fineness-ratio ellipsoids in incompressible flow. As expected for a sphere, the upwash correction is 0 . The upwash correction is also 0 for all axisymmetric ellipsoids at $0^{\circ}$ angle of attack.

As the angle of attack increases, the upwash correction becomes larger, peaking between $45^{\circ}$ and $53^{\circ}$ effective angle of attack (depending on fineness ratio). The upwash correction decreases beyond the peak angle of attack. As fineness ratio increases, the upwash increases as well, reaching an apparent upper limit for an ellipsoid with a fineness ratio greater than 15. As was the case with $\varepsilon$, the upwash parameter can be approximated with a polynomial in effective angle of attack for a given Mach number.

The sensitivity of the upwash correction to variations in angle of sideslip was investigated for ellipsoids with

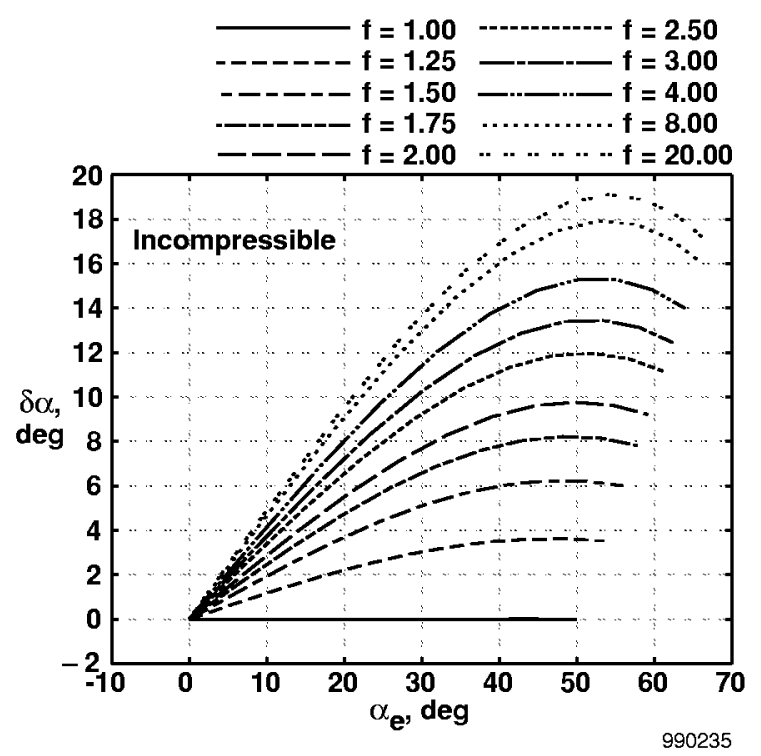

Figure 10. Variation of upwash correction with effective angle of attack for varying fineness-ratio ellipsoids. varying fineness ratios. Figure 11 shows the angle-ofattack error introduced, using the calibration generated for $0^{\circ}$ angle of sideslip, at a nonzero angle of sideslip at $30^{\circ}$ angle of attack. In all cases, the angle-of-attack error is negligible. The error can be larger for nonaxisymmetric bodies, as is shown in the next section.

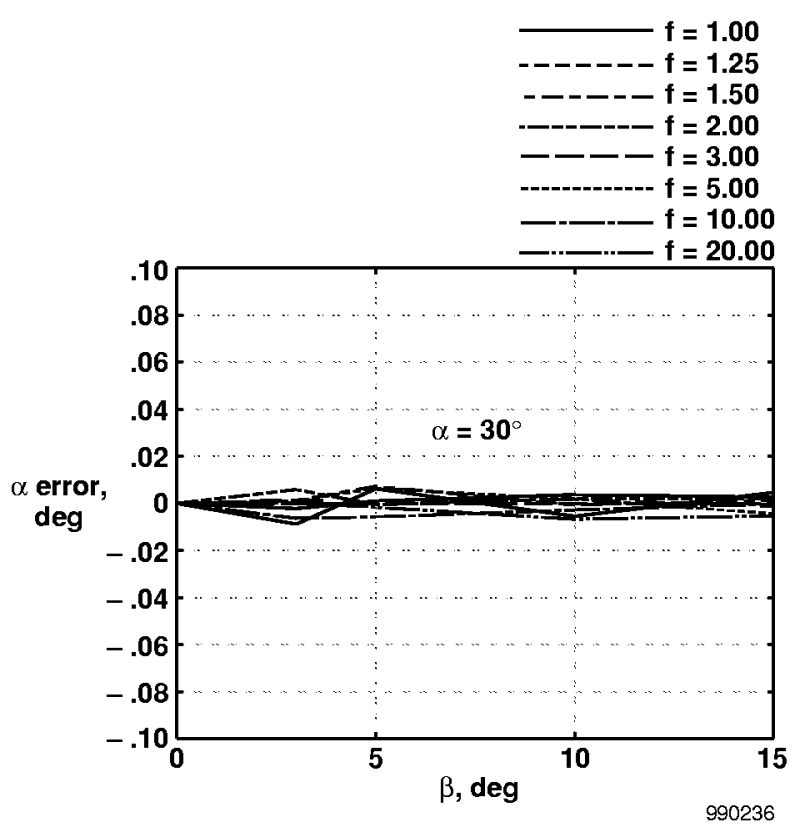

Figure 11. Angle-of-attack error introduced by neglecting the sideslip effect on the $\varepsilon$ calibration.

\section{Calibration of the Sidewash Correction}

Because the ellipsoid is axisymmetric, the sidewash correction at $0^{\circ}$ angle of attack is identical to the upwash correction at $0^{\circ}$ angle of sideslip. The upwash correction was previously shown to be independent of sideslip for moderate sideslip angles. The sidewash correction, however, can be a significant function of angle of attack.

Figure 12 shows the error obtained using the ellipsoid $0^{\circ}$ angle-of-attack sidewash calibration at $30^{\circ}$ angle of attack. As the ellipsoid deviates from a sphere, the sideslip error increases, reaching 25 percent for a fineness ratio of 3.0 at $5^{\circ}$ angle of sideslip. As a result, most wind-tunnel calibration efforts will require both angle-of-attack and -sideslip sweeps to gather sufficient data. 


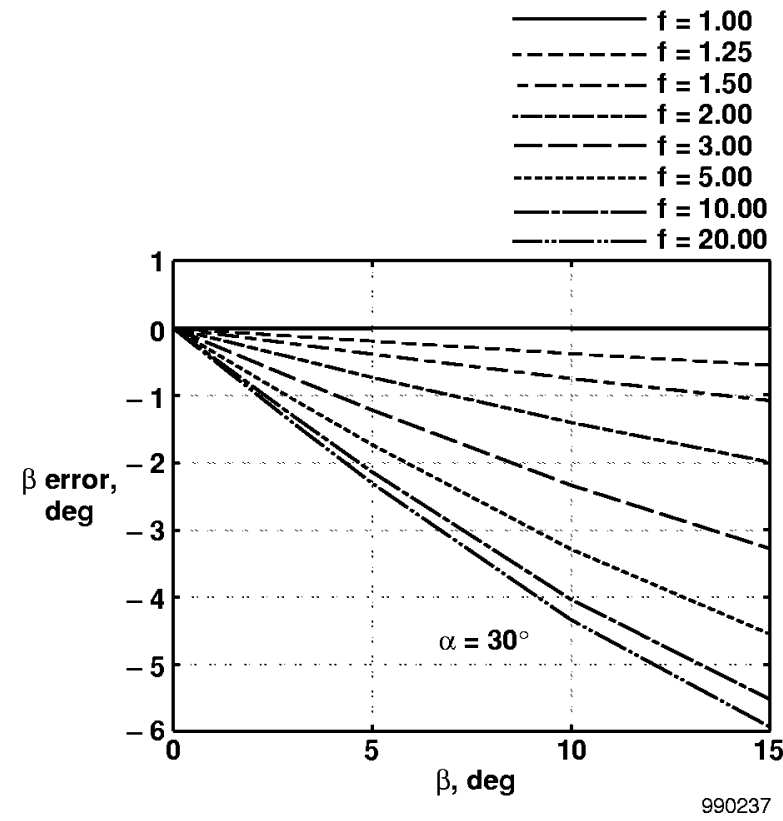

Figure 12. Sideslip error introduced by neglecting angle-of-attack effect on the $\varepsilon$ calibration.

\section{Blunt-Body Wind-Tunnel and Flight Data}

A study of the FPM using the analytically calculated ellipsoid pressure data has revealed the general behavior of the calibration with varying vehicle shape and orientation to the free-stream flow field. The analytical model, however, lacks important flow features that most atmospheric vehicles encounter: Mach number (compressibility), Reynolds number, and flow separation effects. Data from a series of wind-tunnel experiments and from flight tests are used in the following section to evaluate the FADS model characteristics for a variety of vehicles at realistic flight conditions.

\section{Effect of Flow Separation}

The FPM is based on potential flow over a sphere. This model assumes that the fluid flow is always attached over the region of interest, primarily where the ports are located. Wind tunnel-derived pressure distributions on a sphere at two Reynolds numbers are used to study the breakdown of the FPM under separated flow conditions.

Figure 13 shows pressure distributions measured on a sphere $^{23}$ at a Reynolds number based on a diameter of approximately $4.5 \times 10^{5}$; the potential flow solution for a sphere; and the calibrated FPM. At this Reynolds number, the flow stays attached to an incidence angle of

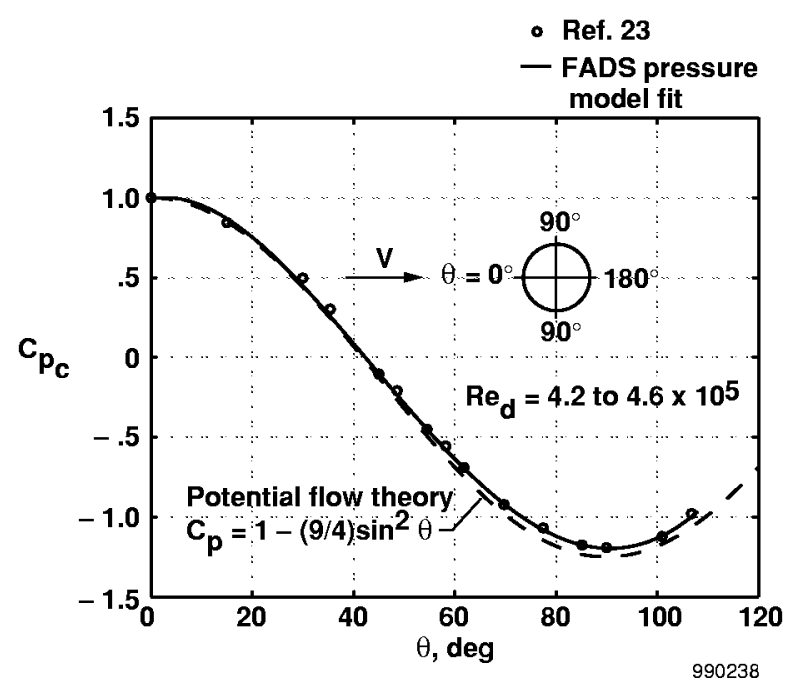

Figure 13. Comparison of FPM and wind-tunnel impact-pressure coefficient on a sphere, $\operatorname{Re}_{d}=4.2$ to $4.6 \times 10^{5}$.

more than $110^{\circ}$ and the calibrated FPM does an excellent job of modeling the pressure distribution.

At lower Reynolds numbers $\left(\operatorname{Re}_{d}=1.6 \times 10^{5}\right)$, however, a laminar separation occurs at approximately $60^{\circ}$ incidence angle (fig. 14). Attempting to calibrate the FPM for the $0^{\circ}-110^{\circ}$ range of incidence angle results in a poor match. Restricting the incidence-angle range to

- Ref. 23

--- FPM calibrated using ports in attached flow

- FPM calibrated using ports in separated flow

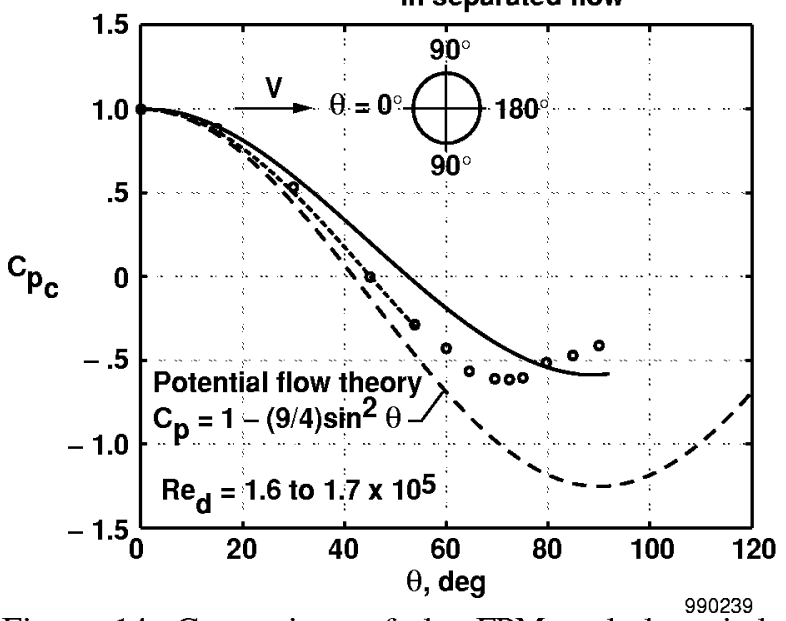

Figure 14. Comparison of the FPM and the windtunnel impact-pressure coefficient on a sphere, $\operatorname{Re}_{d}=1.6$ to $1.7 \times 10^{5}$. 
the ports in the attached flow region results in a good model of the pressure distribution. Using wind-tunnel data to identify the flight conditions at which individual ports have separated flow is generally conservative, because the full-scale flight data usually are at higher Reynolds numbers (delayed separation).

Two methods exist of enforcing the restriction on using ports in separated flow regimes. One method is to locate ports so that separation does not occur in the flight envelope of interest. For the X-33 vehicle, the largest port cone angle on the leeward vertical meridian is $20^{\circ}$, which does not have separated flow to a maximum of $45^{\circ}$ angle of attack. An alternate port arrangement method is to adjust the ports that are used in the FADS algorithm based on flight condition. This method is complex, possibly requiring multiple calibrations and data smoothing during transitions between port sets.

\section{Validation of the Flush Airdata Sensing Pressure Model}

Pressure distributions measured during the windtunnel tests of the 8-deg cone, X-33 forebody, and Rankine half-body were used to validate the pressure modeling capability of the FPM from Mach 0.40 to Mach 4.75 from $-4^{\circ}$ to $30^{\circ}$ angle of attack. Because some of the ports on the nosecap were in or near separation zones at high angles of attack, a realistic subset of the available ports was used in the calibration algorithm to estimate $\varepsilon$. Experience on F-18 and X-33 FADS systems ${ }^{2,3,10}$ and analysis of the wind-tunnel data were used to select a reasonable set of ports: 1, 2, 3, 4, 5, and 10 (fig. 4). Other combinations of ports could be used; however, the simplified FADS solution algorithm described in this paper requests a minimum of five ports, three of which must be in a vertical line for angle-of-attack estimation.

Figure 15(a) shows pressure distributions over the axisymmetric, spherically blunted 8-deg nosecone configuration and the calibrated FPM for Mach numbers of $0.4,0.9,1.2$, and 3.5 at $0^{\circ}$ angle of attack. In each case, the pressure distribution is well-modeled to greater than $45^{\circ}$ incidence angle. A small difference in the $60^{\circ}$ incidence-angle ports- - which were not used to calibrate the shape-is noted. A challenging test for the model is to accurately model the high-angle-of-attack pressure distributions. Figure 15(b) shows the pressure distributions and FPM fit at $30^{\circ}$ angle of attack for subsonic to high supersonic Mach numbers. The FPM accurately models the pressure distribution to a minimum of $60^{\circ}$ flow incidence angle for all Mach numbers.
Unlike the ellipsoid and the 8-deg cone, the X-33 forebody model is not axisymmetric. Figures 16(a) and 16(b) show the FPM fit of the measured X-33 forebody pressure distributions for Mach numbers of $0.4,0.9,1.2$, and 3.5 at angles of attack of $0^{\circ}$ and $30^{\circ}$, respectively. As with the 8-deg nosecone, the pressure distribution is well-modeled to $45^{\circ}$ incidence angle, with some degradation occurring at $60^{\circ}$. At $30^{\circ}$ angle of attack, the pressure distribution is well-modeled to greater than $60^{\circ}$ incidence angle. No degradation in the FPM predictive capability was found for any of the Mach numbers or angles of attack tested.

Although axisymmetric, the nose of the Rankine halfbody does not have a spherical shape. The ellipsoid data previously shown confirmed that the FPM was adaptable to nonspherical shapes in incompressible flow fields. Figures 17(a) and 17(b) show the pressure distributions measured on the nosecap of the Rankine half-body wind-tunnel model for Mach numbers of 0.4 , $0.9,1.2$, and 3.5 at angles of attack of $0^{\circ}$ and $30^{\circ}$, respectively. Because this model violates the spherical shape upon which the FADS model is based, some degradation in the predictive capability might be expected. This expectation is not the case, however, as the fit is shown to be as good as with either of the two spherically blunted nosecone models. These data confirm that the FADS pressure model can be successfully applied to nonspherical shapes from subsonic to supersonic Mach numbers, thereby extending the incompressible ellipsoid study findings to higher Mach numbers.

\section{Calibration of the Shape and Compressibility Parameter}

Figures 18(a)-(d) show the $\varepsilon$ calibrations for the spherically blunted 8-deg nosecone, Rankine half-body, $\mathrm{X}-33$ vehicle, and $\mathrm{X}-33$ forebody. The character of the calibration is similar for each forebody shape. At subsonic Mach numbers, $\varepsilon$ decreases with increasing effective angle of attack. For the axisymmetric 8-deg cone (fig. 18(a)) and Rankine half-body shapes (fig. 18(b)), the peak of the curve is at $0^{\circ}$ angle of attack for subsonic and transonic Mach numbers. This peak location is expected because the flow behavior is symmetrical for positive and negative incidence angles on an axisymmetric shape. The X-33 vehicle, however, is not symmetric along the upper and lower surfaces aft of the spherically blunted nosecap. This asymmetry results in a peak $\varepsilon$ value at a nonzero angle of attack that is especially evident for the complete X-33 configuration (fig. 18(c)). 


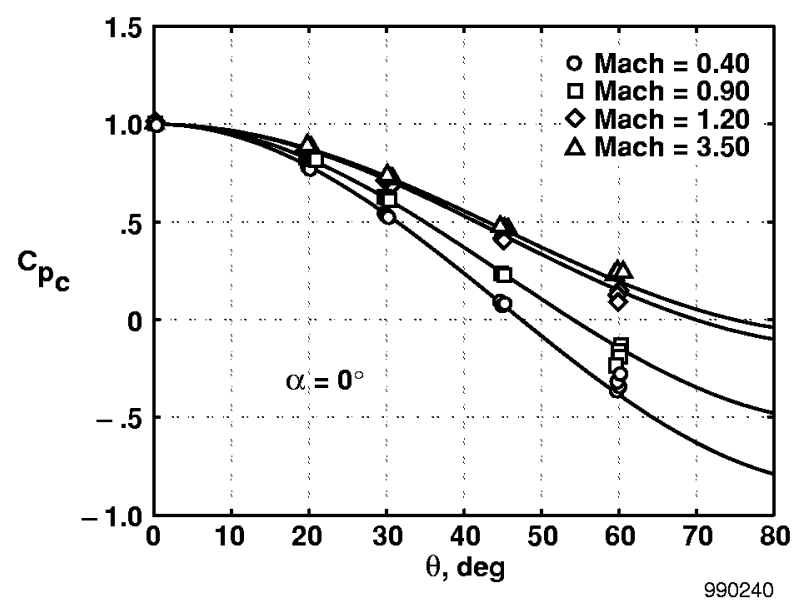

(a) $\alpha=0^{\circ}$.

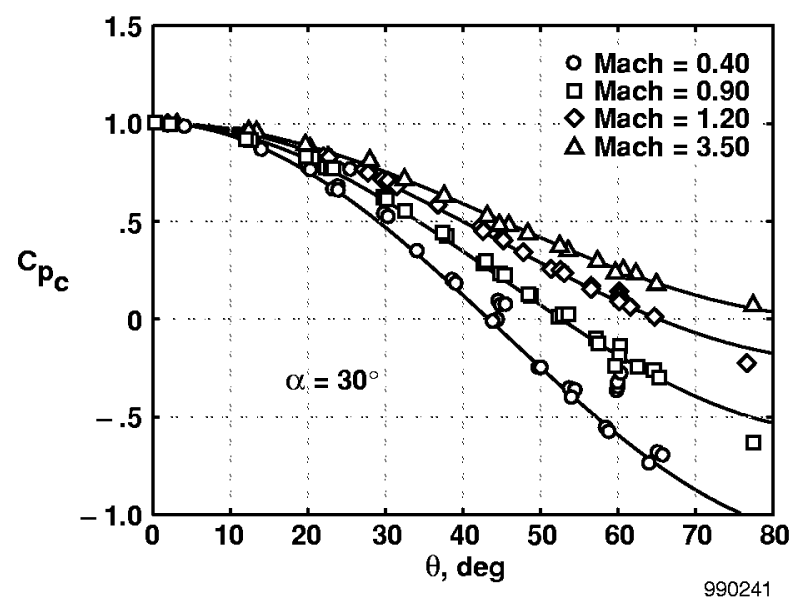

(b) $\alpha=30^{\circ}$.

Figure 15. Comparison of the FPM and the measured impact-pressure coefficient as a function of flow incidence angle, 8-deg cone.

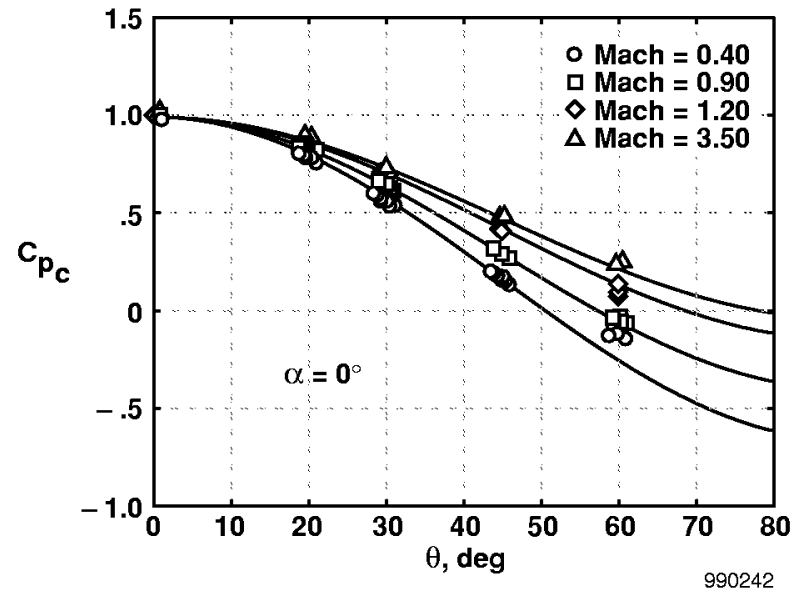

(a) $\alpha=0^{\circ}$.

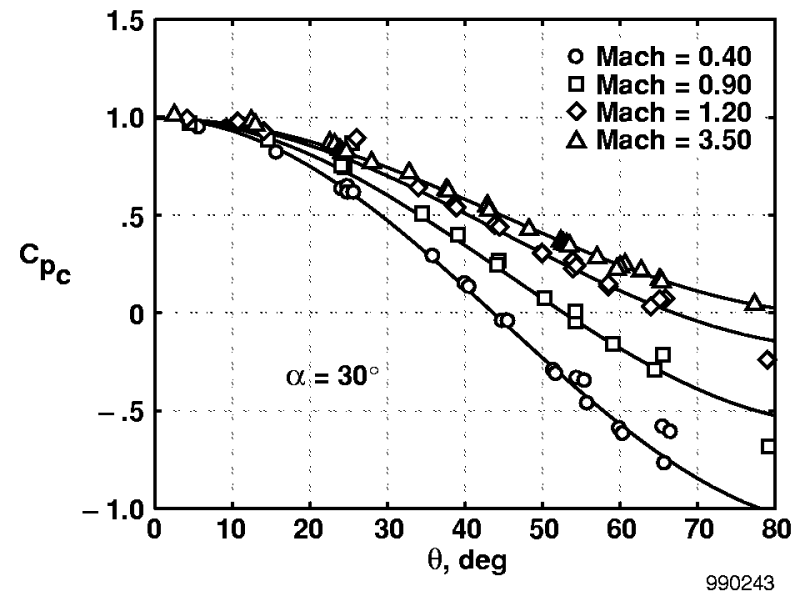

(b) $\alpha=30^{\circ}$.

Figure 16. Comparison of the FPM and the measured impact-pressure coefficient as a function of flow incidence angle, X-33 forebody. 


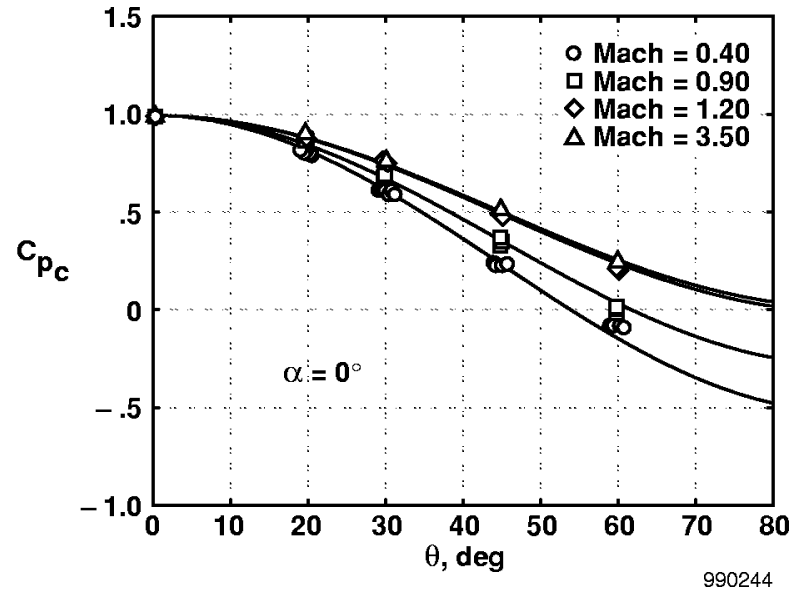

(a) $\alpha=0^{\circ}$.

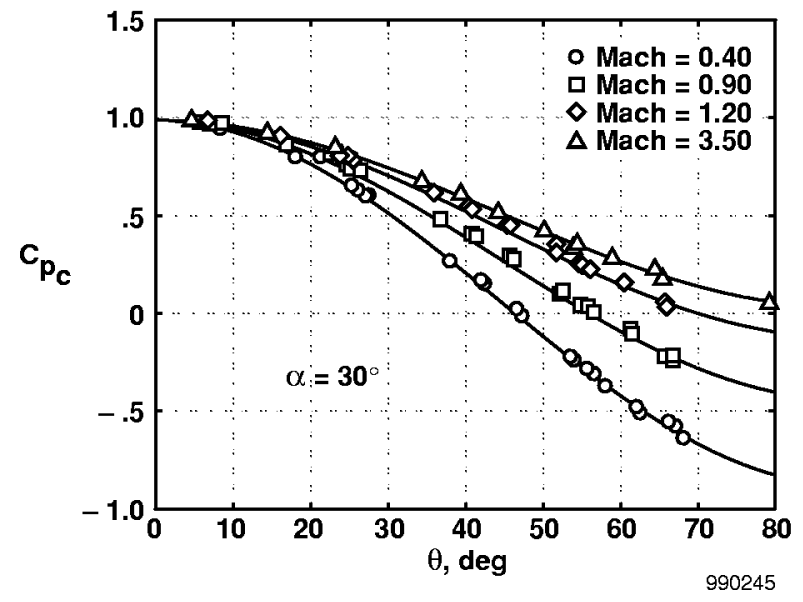

(b) $\alpha=30^{\circ}$.

Figure 17. Comparison of the FPM and the measured impact-pressure coefficient as a function of flow incidence angle, Rankine half-body.

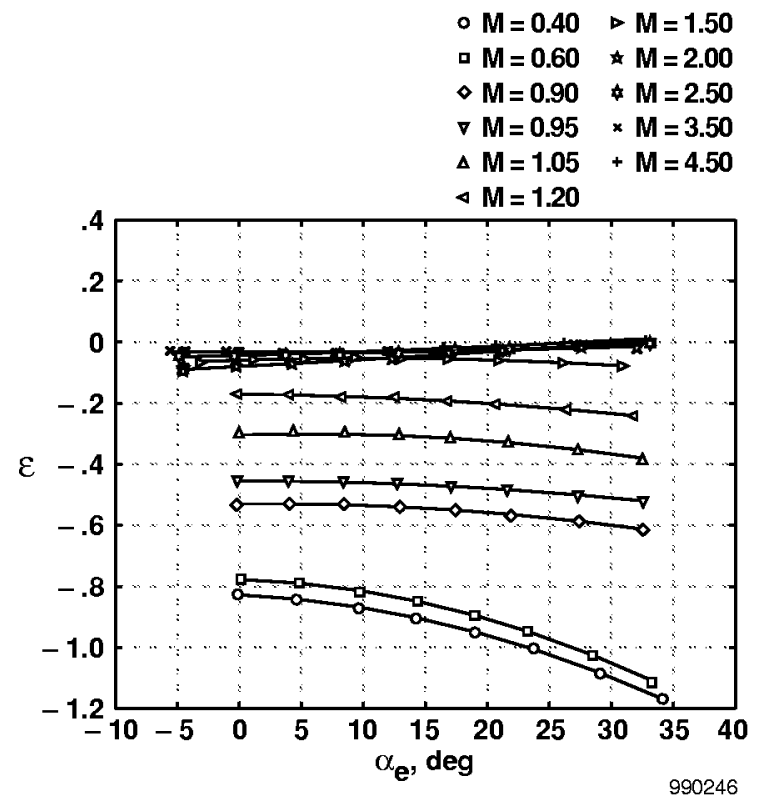

(a) 8-deg cone calibration.

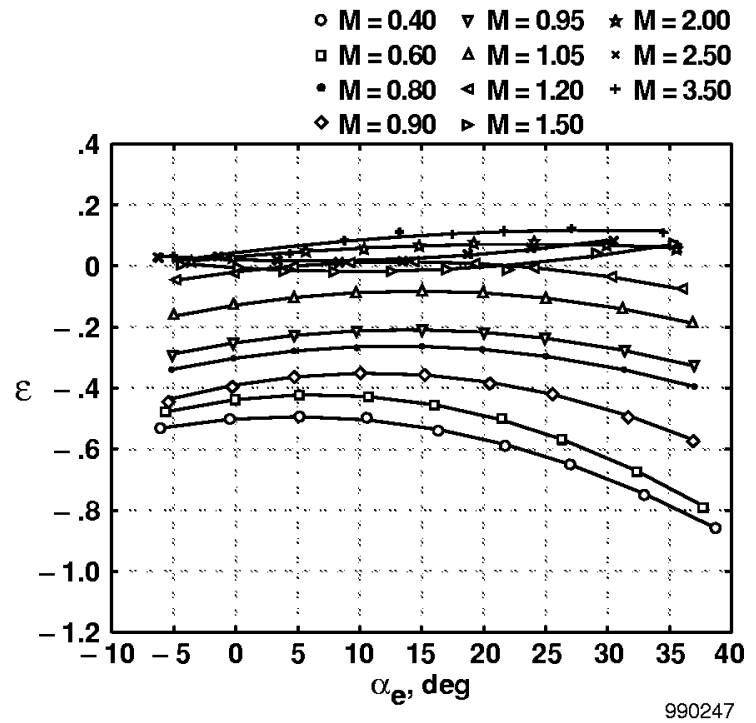

(b) Rankine half-body calibration.

Figure 18. FPM calibrations. 


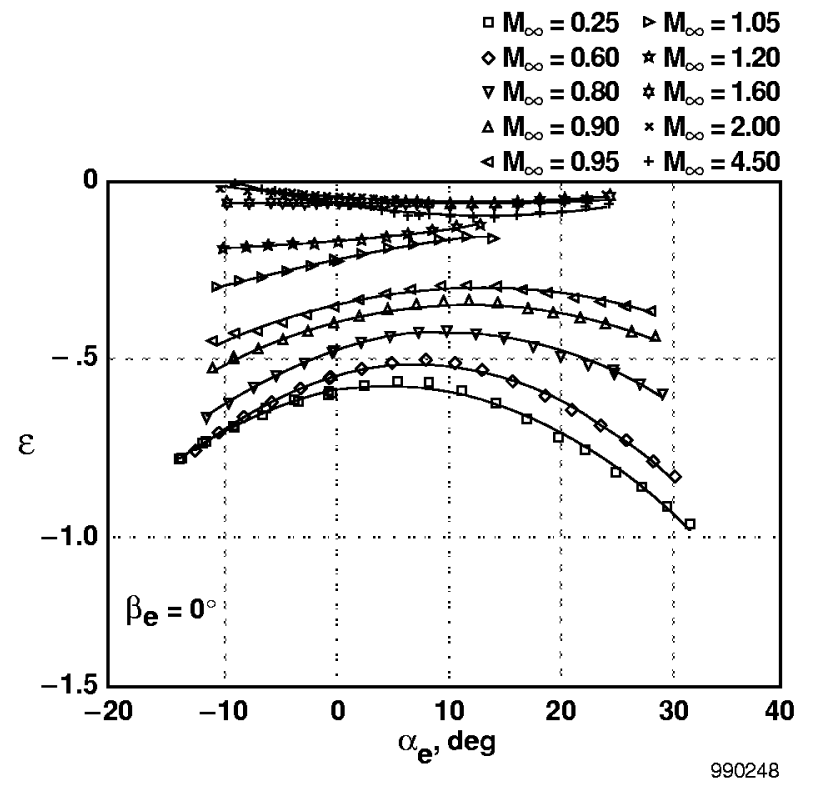

(c) X-33 calibration.

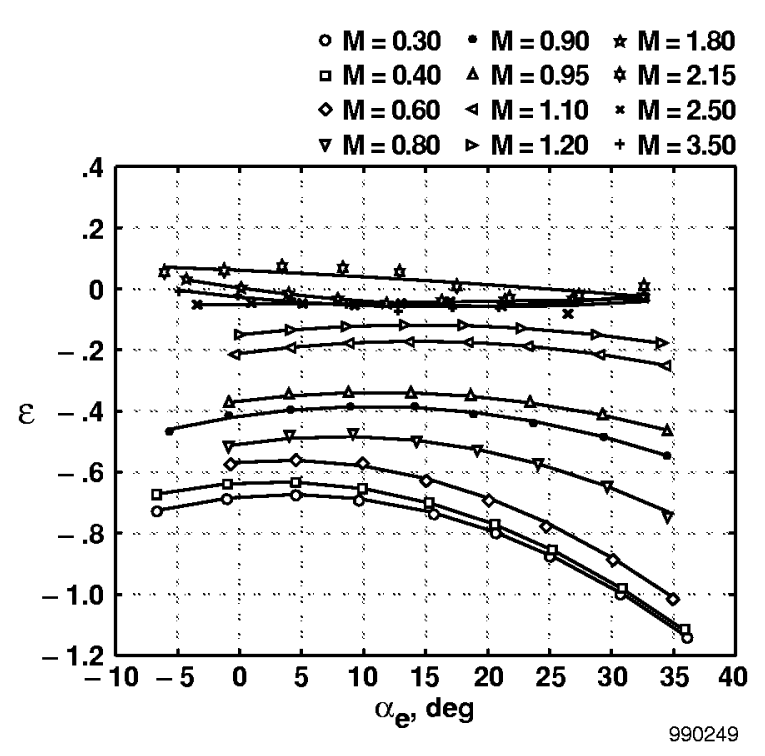

(d) X-33 forebody calibration.

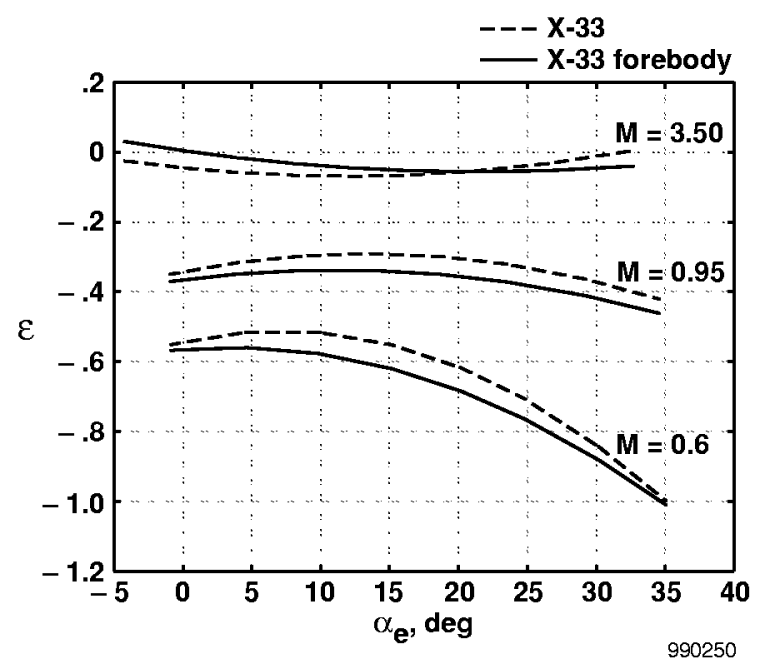

(e) Comparison of full and forebody-only X-33 calibrations.

Figure 18. Concluded. 
For Mach numbers less than 1.0, the angle of attack of the $\varepsilon$ peak increases with increasing Mach number. A comparison of figures $18(\mathrm{c})$ and $18(\mathrm{~d})$ reveals differences between the X-33 and X-33-forebody calibrations at subsonic and transonic Mach numbers. Figure 18(e) shows a comparison of the complete and forebody-only X-33 configurations at Mach 0.60, 0.95, and 3.50. The calibration differences indicate that calibration of a blunt-body FADS system requires a complete configuration be tested to ensure that adequate data are obtained.

Although the different forebody shapes have different values of $\varepsilon$ at low Mach numbers, all calibrations converge to a value near 0 at supersonic Mach numbers. As stated earlier, the FPM reduces to Newtonian impact theory as $\varepsilon$ approaches 0 . The calibrations show that Newtonian impact theory is an accurate predictor of the surface pressures for these blunt bodies beginning at approximately Mach 2.0. The second-order nature of the $\varepsilon$ calibration with angle of attack reduces such that at high supersonic Mach numbers, $\varepsilon$ is nearly independent of angle of attack.

Figure 19 shows a comparison of the $\varepsilon$ calibration for three (X-33, X-34, and X-38) FADS systems in development for low subsonic speeds. The $\mathrm{X}-33$ data are from the wind-tunnel test of the complete $X-33$ vehicle. $^{2}$ Both the $\mathrm{X}-33$ and $\mathrm{X}-38$ lifting bodies have camber that results in a peak in the $\varepsilon$ curve at an effective angle of attack slightly greater than $0^{\circ}$. The X-34 plot, however, has an $\varepsilon$ curve that peaks at an effective angle of attack of approximately $19^{\circ}$. Although the FADS ports are located symmetrically around the $\mathrm{X}-34$ axisymmetric forebody, the forebody itself is

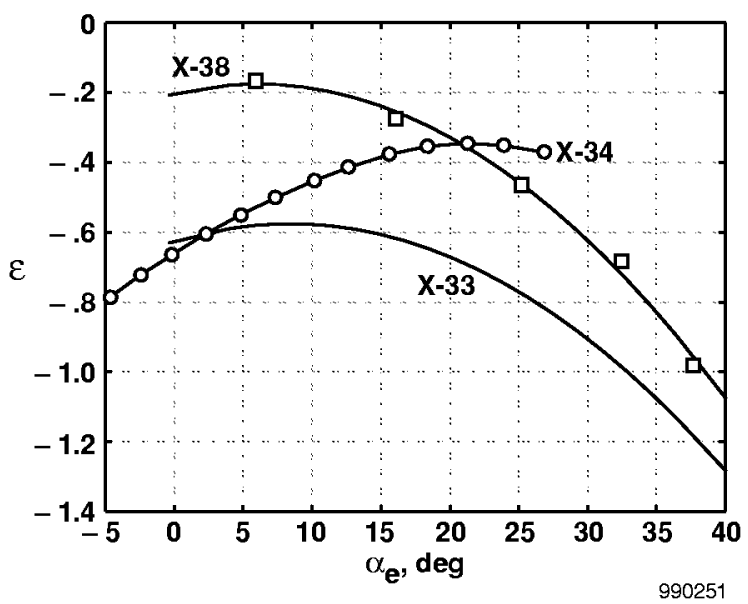

Figure 19. Comparison of X-33, X-34, and X-38 FPM calibrations, $\mathrm{M} \approx 0.3$. rotated down $16.1^{\circ}$ from the vehicle reference line, causing the shift in the $\varepsilon$ peak. The most important feature of the $\varepsilon$ calibration is that it is adaptable to a wide variety of realistic forebody shapes.

To further study the Mach number effect on the calibrations, $\varepsilon_{\mathrm{M}}$ was defined as the peak of the curves of $\varepsilon$ as a function of $\alpha_{e}$. Figure 20 shows $\varepsilon_{\mathrm{M}}$ as a function of Mach number for the 8-deg cone; Rankine half-body; X-33 forebody; X-33, X-34, X-38, F/A-18 SRA, and F-14 vehicles; hemispherical-head cylinder; and 12.5-deg, 18-deg, and 45-deg spherically blunted cones. In all cases, the value of $\varepsilon$ is a smooth, continuous, monotonic function of Mach number. This characteristic is an important difference from traditional pitot-static airdata system calibrations, which typically are characterized as having sharp changes in the position error calibration $^{1}$ in the transonic Mach region.

An obvious outcast in figure 20 is the $\varepsilon_{M}$ calibration for the F/A-18 SRA. The value of $\varepsilon$ is positive for low Mach numbers, rises slightly in the transonic region, and then decreases. If calibration data were achievable at high Mach numbers on the F/A-18 SRA, $\varepsilon_{M}$ would be expected to converge to zero (modified Newtonian theory). The likely reason for the difference in shape of the $\varepsilon$ calibration is that the region over which the FADS pressures operate on the SRA is in the first $2 \mathrm{in.}$ of the forebody. The large afterbody of the F/A-18 SRA in relation to the forebody region causes higher pressure in the nosetip area, resulting in a higher $\varepsilon_{M}$. The result of the foregoing discussion is that traditional fighter forebody configurations may have different calibration shapes than blunt-body configurations (for example,

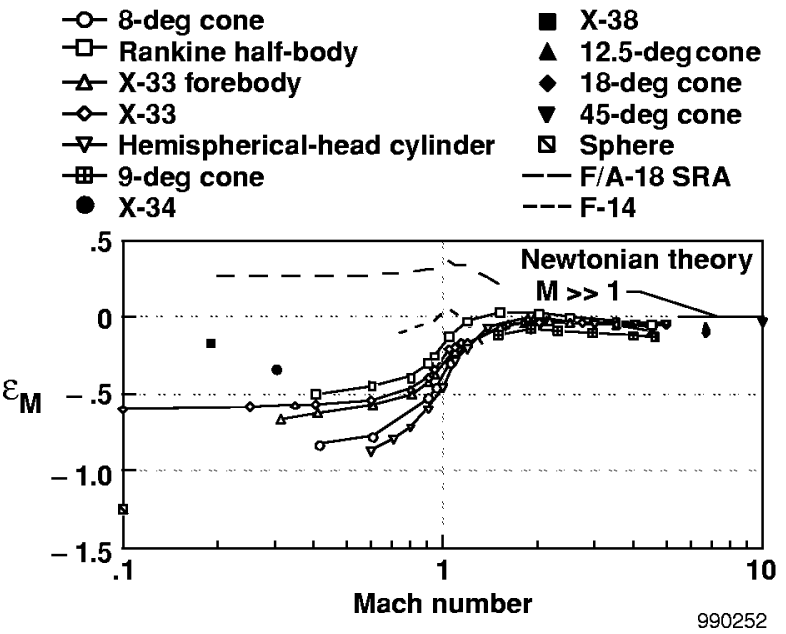

Figure 20. Variation of FPM calibration with Mach number. 
$\mathrm{X}-33, \mathrm{X}-38$, and Space Shuttle configurations); however, the FPM still yields results with equivalent levels of accuracy.

Figure 21 shows the variation of $\varepsilon$ with angle of sideslip for the X-33 vehicle. At subsonic Mach numbers, $\varepsilon$ slightly depends on $\beta$. Over the angle-ofsideslip range of interest (less than $5^{\circ}$ for the $X-33$ vehicle), the adjustment caused by angle of sideslip is small. The angle-of-sideslip effect is negligible at transonic and (as expected) supersonic Mach numbers.

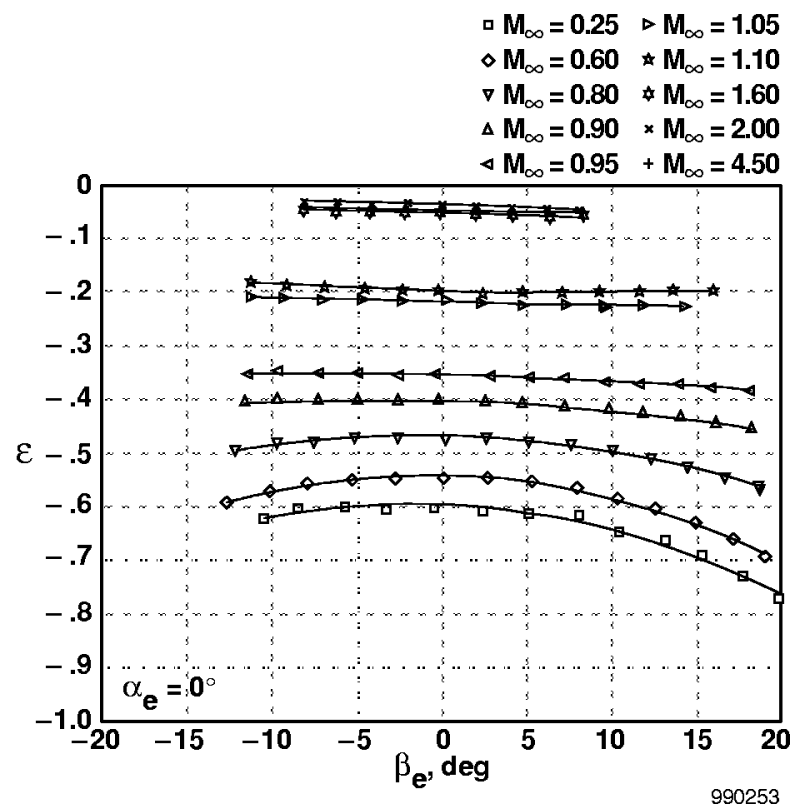

Figure 21. X-33 FPM calibration variation with sideslip.

\section{Calibration of Upwash Correction}

An upwash calibration parameter, $\delta \alpha$, is needed to calculate true angle of attack from the effective (locally measured) angle of attack, $\alpha_{e}$, according to equation (4). Figure 22 shows the upwash calibration for the three forebody models. All three blunt-body configurations have upwash calibrations that increase with increasing effective angle of attack to a peak value between $25^{\circ}$ and $40^{\circ}$ effective angle of attack at subsonic and transonic Mach numbers. Although data are limited, the upwash correction appears to decrease at high effective angles of attack, as was seen with the ellipsoid shapes (fig. 10).

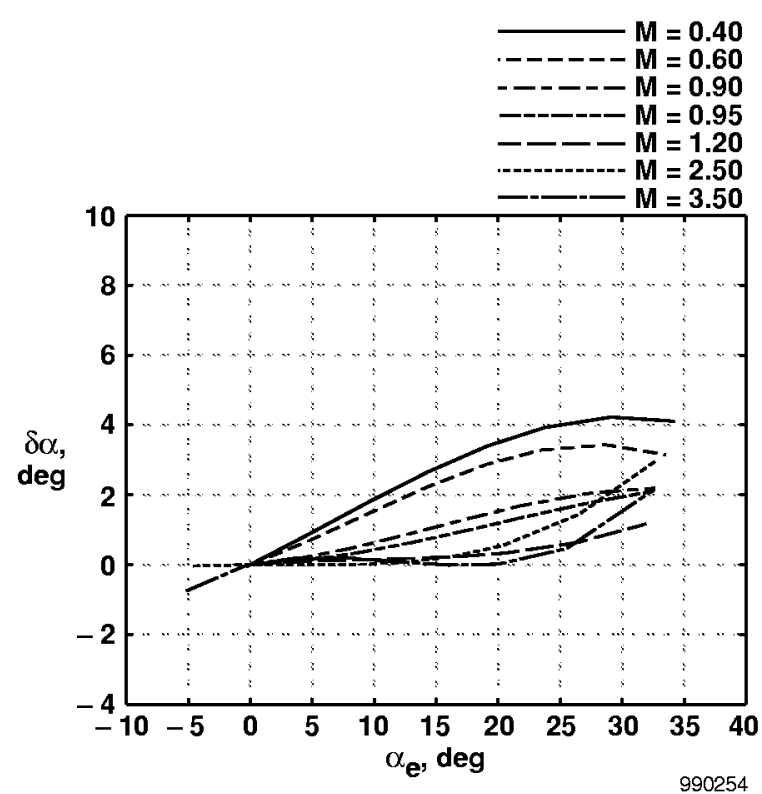

(a) 8-deg cone calibration.

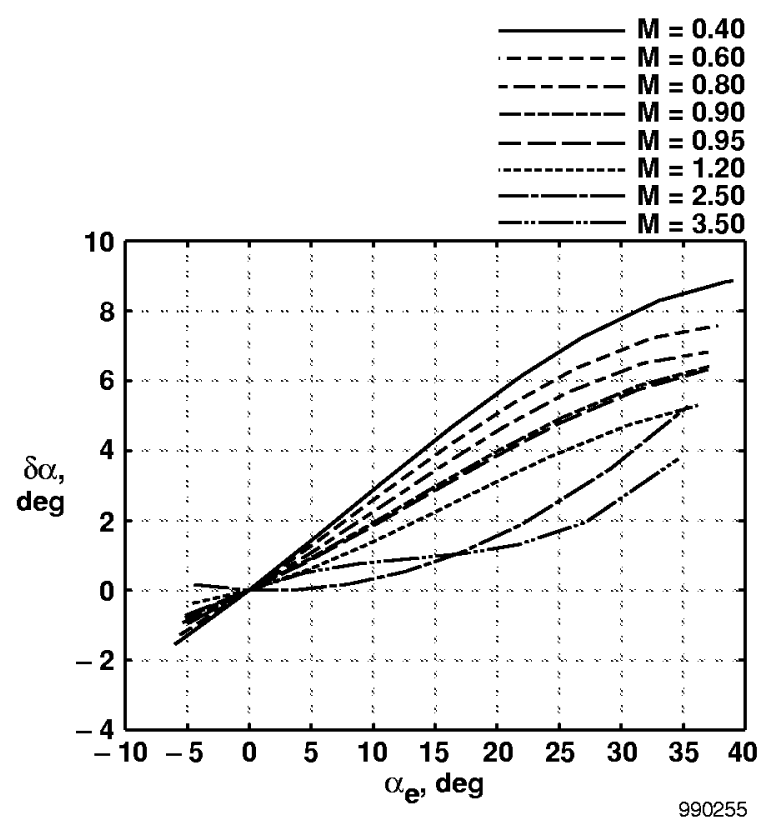

(b) Rankine half-body calibration.

Figure 22. Upwash calibrations. 


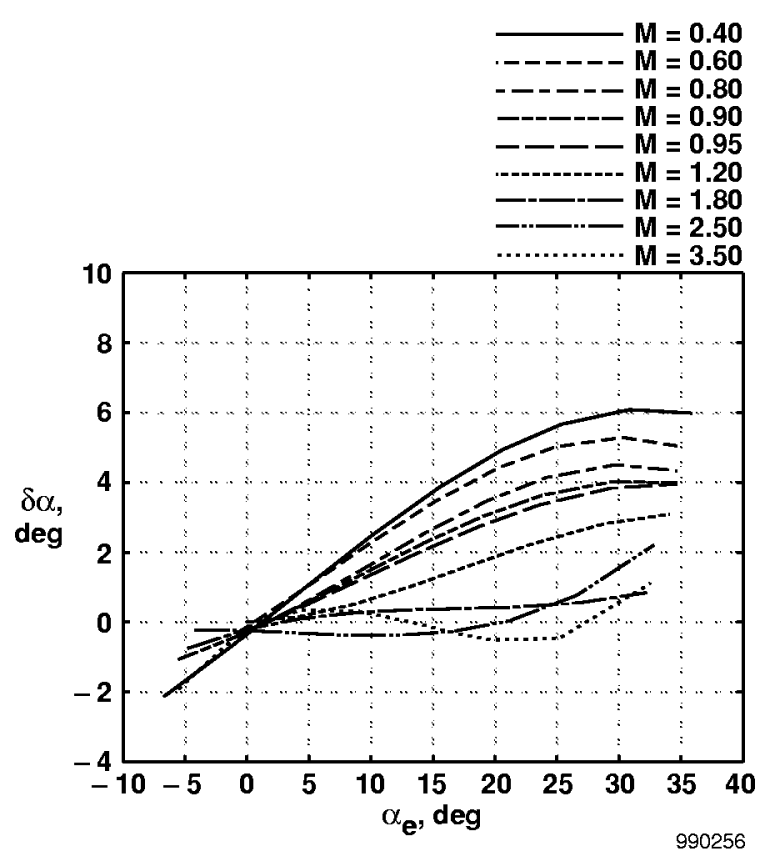

(c) X-33 forebody calibration.

Figure 22. Concluded.

Figure 23 shows the upwash calibration for the complete X-33 configuration. The calibration is a smooth, polynomial function of effective angle of attack that decreases with increasing Mach number. The plots

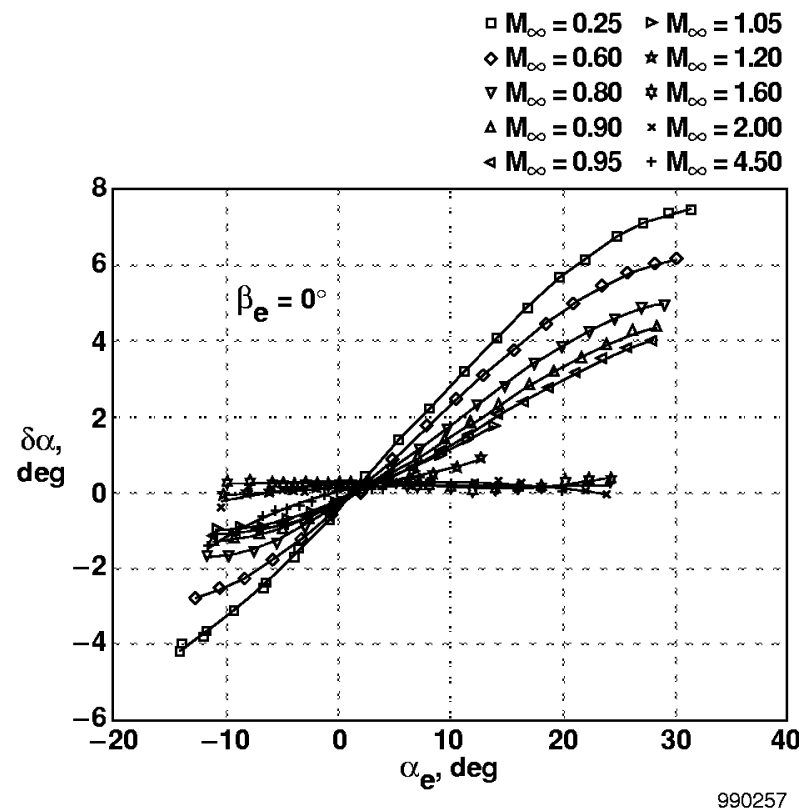

Figure 23. X-33 upwash calibration. show that the upwash correction reduces to approximately $0.25^{\circ}$ at Mach 1.6 and greater. This reduction is expected at supersonic Mach numbers because the flow field is not disturbed by the model until the shock wave is encountered. The actual correction that will be used by the X-33 vehicle will normally be less than $3^{\circ}$ based on the current Mach number and angle-of-attack trajectories.

An important operational consideration is whether the FADS calibration can be easily implemented into a realtime estimator. Because the upwash calibration is a smooth, monotonic function of effective angle of attack, it can be represented as a simple polynomial or table lookup.

A comparison between the X-33 and X-33 forebody upwash corrections (figs. 22(c) and 23) reveal differences of $1^{\circ}$ in some cases. Again, this result indicates that the complete vehicle configuration must be used during blunt-body FADS calibration windtunnel tests.

Figure 24 shows the upwash correction for the X-33, $\mathrm{X}-34$, and X-38 forebodies at low subsonic Mach numbers. The slope of the upwash correction indicates that the X-38 model generated the largest upwash of the set. At $20^{\circ}$ true angle of attack (approximately $37^{\circ}$ effective angle of attack), the X-38 upwash correction is a large $17^{\circ}$. In contrast, the X-33 upwash correction at $20^{\circ}$ true angle of attack (approximately $27^{\circ}$ effective angle of attack), is only approximately $7^{\circ}$. The larger $\mathrm{X}-38$ upwash is caused by the larger thickness ratio of the fuselage.

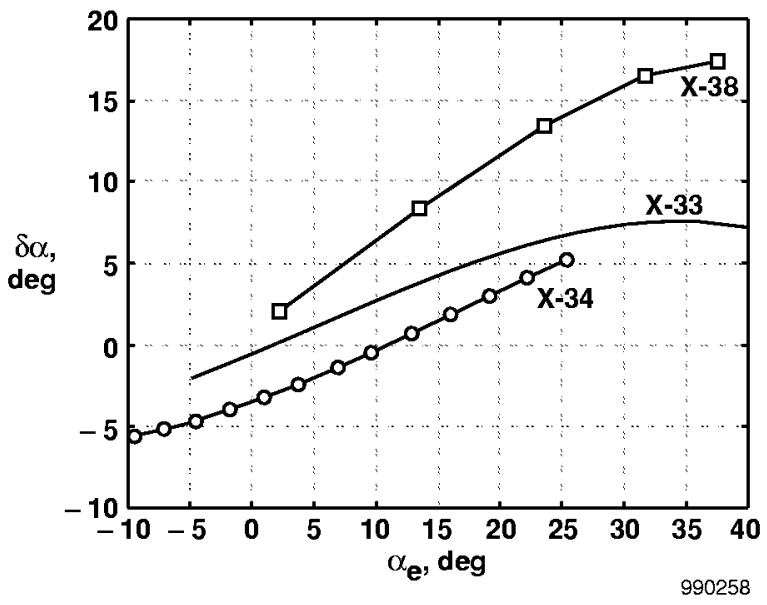

Figure 24. Comparison of X-33, X-34, and X-38 upwash calibrations, $\mathrm{M} \approx 0.3$. 


\section{Calibration of Sidewash Correction}

For the axisymmetric shapes, $\delta \beta$ at $0^{\circ}$ angle of attack is exactly the same as $\delta \alpha$ at $0^{\circ}$ angle of sideslip. For nonaxisymmetric shapes such as the X-33 vehicle, the sidewash calibration will obviously differ. Figure 25 shows the sidewash calibration, $\delta \beta$, for the complete $\mathrm{X}-33$ configuration. The sidewash calibration is similar in character to the X-33 upwash calibration (fig. 23), although the magnitude is approximately one-half of the upwash calibration at subsonic Mach numbers. The upwash correction should be larger than the sidewash correction, because the vehicle develops more lift with angle-of-attack changes than it does sideforce with angle-of-sideslip changes. As with the upwash calibration, the important feature is that the sidewash calibration is a smooth, monotonic function that is easily represented by a polynomial equation.

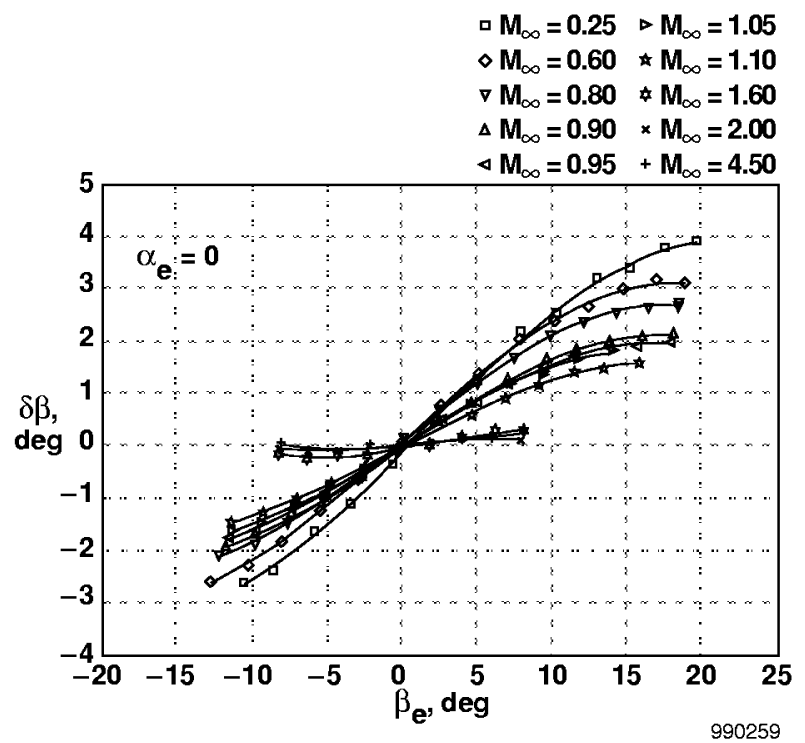

Figure 25. X-33 sidewash calibration.

For the X-33 FADS calibration, ${ }^{2}$ the error in neglecting the angle-of-attack effect on the angle of sideslip was less than $0.5^{\circ}(1 \sigma)$ from Mach 0.2 to Mach 4.5. Thus, the dependence of the sidewash calibration on angle of attack is configurationdependent. A configuration that has a significant angleof-attack effect on the sidewash will require considerably more wind-tunnel runs to calibrate than one that does not.

\section{Port Sensitivity}

Initially, the calibration of the upwash and sidewash parameters was believed to be configuration-dependent but independent of the port locations. This idea came from early tests of the F/A-18 HARV, which showed only minor changes in the calibration with changes in the ports used in the model. Current wind-tunnel tests of the X-33 vehicle, X-33 forebody, 8-deg cone, and Rankine half-body, however, have shown the upwash calibration is somewhat dependent on the port layout for blunt bodies.

Figure 26 shows the upwash calibration for several combinations of ports in the vertical meridian on the 8-deg spherical nosecone at Mach 0.9. Because the FADS solution algorithm requires three ports on a vertical meridian, a total of ten different three-port arrangements (triples) are possible from the five ports shown. The variation between the corrections $(\delta \alpha)$ is approximately $0.5^{\circ}$ at angles of attack less than $10^{\circ}$. At greater than $10^{\circ}$ angle of attack, the upwash correction tends to be port-dependent. Port combinations that are distributed symmetrically about the model longitudinal axis (that is, triples $[1,2,4]$ or $[1,4,6]$ ) have corrections that are less than $1^{\circ}$ to angles of attack greater than $30^{\circ}$. Triples that are clustered well below or above the vehicle axis of symmetry (that is, triples $[2,6,10]$ or $[1,6,10])$ have the largest corrections.
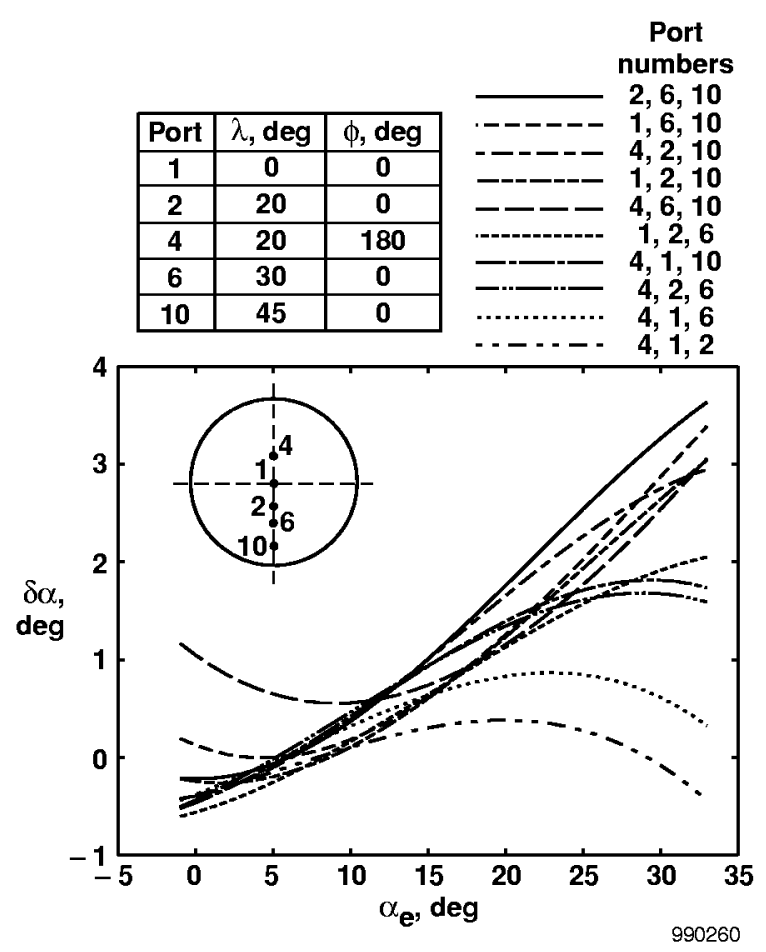

Figure 26. Variation of upwash calibration with por1 selection, 8-deg cone. 
A probable cause for the port-dependent upwash calibration is a variation in the vehicle-induced upwash from one flush-mounted port to the next. On a blunt body, the local upwash can significantly vary from location to location because the forebody is a significant portion of the vehicle length. With a nose diameter of approximately 1 in., the F/A-18 vehicle upwash cannot significantly vary between the ports, which would explain why the FADS calibration was essentially portindependent for this vehicle.

An important result of the calibration dependence on the port locations for blunt-body shapes is that the fullscale vehicle must have port locations in approximately the same locations as the calibration model. Because the calibration was previously thought to be independent of the port locations, the flight software was thought to need only the location of the actual vehicle port clock and cone angles. This finding requires that the FADS ports be well-defined before the wind-tunnel calibration tests. Alternately, the wind-tunnel calibration model can be machined with additional ports (a good idea in any case), and the data can be used to help define the proper port locations on the full-scale vehicle. For the X-33 vehicle, internal structural and space limitations also influenced the selection of the port locations.

\section{$\underline{\text { Summary }}$}

The flush airdata sensing (FADS) system pressure model is derived as a synthesis of the incompressible potential flow around a sphere and modified Newtonian flow theory. The pressure model and its solution algorithm provide a method for extracting the entire airdata parameter state vector-except true airspeedfrom flush surface pressure measurements. This paper uses analytical and empirical data to calibrate the FADS pressure model (FPM) for numerous blunt-forebody configurations. The sources of the forebody pressure data are as follows:

- Analytical solutions for axisymmetric ellipsoids with fineness ratios from 1 to 20 and free-stream angles of attack from $0^{\circ}$ to $70^{\circ}$.

- Wind-tunnel tests of three blunt-forebody shapesan 8-deg cone, a Rankine half-body, and an X-33 forebody - with Mach numbers ranging from 0.3 to 4.5 and angles of attack from $-4^{\circ}$ to $30^{\circ}$.

- Wind-tunnel tests of X-33, X-34, and X-38 complete-vehicle models, with Mach numbers ranging from 0.3 to 4.8 and angles of attack from $-10^{\circ}$ to $30^{\circ}$.
- Flight data from full-scale tests of an F/A-18 and a modified F-14 aircraft. Flight test range varied from Mach 0.3 to Mach 2.0 and from $-10^{\circ}$ to $50^{\circ}$ angle of attack.

All of the data sets demonstrated the FADS model was generally applicable for blunt forebodies. The general structure of the calibration curves was consistent across the wide range of shapes, scales, Mach numbers, and angles of attack that were tested. No attempt was made to validate the model for sharp-edged or two-dimensional shapes.

Specific lessons learned include the following:

- The FPM-adapted from the solution for potential flow over a sphere_can be calibrated for a wide variety of blunt-forebody shapes.

- The effect of lee-side flow separation is significant. When the surface flow has separated, the measured pressure cannot be accurately modeled by the FPM. Inclusion of pressure ports whose surface flow is separated will dramatically reduce the accuracy of the airdata estimates. Restricting the incidenceangle range to the ports in the attached flow region results in a good model of the pressure distribution. Using wind-tunnel data to identify the flight conditions at which individual ports have separated flow is generally conservative, because the fullscale flight data will usually be at higher Reynolds numbers (delayed separation).

- The calibration parameters are composed of three terms: a shape and compressibility parameter, $\varepsilon$; an upwash parameter, $\delta \alpha$; and a sidewash parameter, $\delta \beta$. Using these three parameters, the FPM was calibrated to equivalent levels of accuracy for each of the data sources analyzed. When plotted as a function of Mach number, angle of attack, and angle of sideslip, the calibration parameters exhibited very similar characteristics.

- All three calibration parameters were found to be smooth, monotonic functions that are easily storable in a real-time system. At high Mach numbers, $\varepsilon$ universally approached 0 , which reduces the FPM to modified Newtonian flow. Also, for Mach numbers greater than approximately 1.5, the variation in $\varepsilon$ with angle of attack and angle of sideslip is negligible.

- The angle-of-attack and -sideslip calibration parameters, $\delta \alpha$ and $\delta \beta$, are generally a function of angle of attack and Mach number; however, at high Mach numbers these values diminish to small, 
constant-bias values. This high Mach number result-along with the earlier conclusion that the effect of angle of attack is negligible at high Mach numbers-greatly reduces the complexity of the calibration matrix, which must be tested for supersonic flow conditions. Furthermore, these results are reassuring in that they verify the FPM converges to modified Newtonian flow theory at high Mach numbers.

- The derived calibrations are sensitive to the port locations. Data presented showed that the forebody upwash calibrations can vary by as much as 20 percent, if ports on the test forebody do not match the location from which the original calibrations were derived.

- Tests of complete and forebody-only X-33 configurations revealed moderate differences in the calibration results at subsonic and transonic Mach numbers. Wind-tunnel tests of FADS calibration should use a complete model of the desired configuration. Usually, FADS calibration data can be obtained simultaneously with traditional force and moment tests.

\section{$\underline{\text { References }}$}

${ }^{1}$ Gracey, William, Measurement of Aircraft Speed and Altitude, NASA RP-1046, 1980.

${ }^{2}$ Whitmore, Stephen A., Brent R. Cobleigh, and Edward A. Haering, Design and Calibration of the X-33 Flush Airdata Sensing (FADS) System, NASA TM-1998-206540, 1998.

${ }^{3}$ Whitmore, Stephen A., Timothy R. Moes, and Terry J. Larson, Preliminary Results From a Subsonic High Angle-of-Attack Flush Airdata Sensing (HI-FADS) System: Design, Calibration, and Flight Test Evaluation, NASA TM-101713, 1990.

${ }^{4}$ Cobleigh, Brent R. and John Del Frate, Water Tunnel Flow Visualization Study of a $4.4 \%$ Scale X-31 Forebody, NASA TM-104276, 1994.

${ }^{5}$ Cobleigh, Brent R., High-Angle-of-Attack Yawing Moment Asymmetry of the X-31 Aircraft from Flight Test, NASA CR-186030, 1994.

${ }^{6}$ Cary, John P. and Earl R. Keener, Flight Evaluation of the X-15 Ball-Nose Flow-Direction Sensor as an Air-Data System, NASA TN-D-2923, 1965.
${ }^{7}$ Siemers, P. M. III, H. Wolf, and P. F. Flanagan, "Shuttle Entry Air Data System Concepts Applied to Space Shuttle Orbiter Flight Pressure Data to Determine Air Data: STS 1-4," AIAA-83-0118, Jan. 1983.

${ }^{8}$ Larson, Terry J., Stephen A. Whitmore, L. J. Ehernberger, J. Blair Johnson, and Paul M. Siemers III, Qualitative Evaluation of a Flush Air Data System at Transonic Speeds and High Angles of Attack, NASA TP-2716, 1987.

${ }^{9}$ Larson, Terry J., Timothy R. Moes, and Paul M. Siemers III, Wind-Tunnel Investigation of a Flush Airdata System at Mach Numbers From 0.7 to 1.4, NASA TM-101697, 1990.

${ }^{10}$ Whitmore, Stephen A., Roy J. Davis, and John Michael Fife, In-Flight Demonstration of a Real-Time Flush Airdata Sensing (RT-FADS) System, NASA TM-104314, 1995.

${ }^{11}$ Currie, I. G., Fundamental Mechanics of Fluids, McGraw-Hill, Inc., New York, 1974.

${ }^{12}$ Anderson, John D., Jr., Hypersonic and High Temperature Gas Dynamics, McGraw-Hill, Inc., New York, 1989.

${ }^{13}$ Bendat, Julius S. and Allan G. Piersol, Random Data: Analysis and Measurement Procedures, John Wiley \& Sons, Inc., New York, 1986.

${ }^{14}$ Shapiro, Ascher H., The Dynamics and Thermodynamics of Compressible Fluid Flow, vol. 1, The Ronald Press Company, New York, 1953, pp. 83-88, 154.

${ }^{15}$ Haering, E. A., Jr., “Airdata Calibration Techniques for Measuring Atmospheric Wind Profiles," Journal of Aircraft, vol. 29, no. 4, Jul.-Aug. 1992, pp. 632-639.

\footnotetext{
${ }^{16}$ Whitmore, Stephen A. and Timothy R. Moes, Measurement Uncertainty and Feasibility Study of a Flush Airdata System for a Hypersonic Flight Experiment, NASA TM-4627, 1994.
}

${ }^{17}$ Franklin, Gene F. and J. David Powell, Digital Control of Dynamic Systems, Addison-Wesley Publishing Co., Inc., Reading, Massachusetts, 1980.

${ }^{18}$ Råde, Lennart and Bertil Westergren, Beta Mathematics Handbook, 2nd ed., CRC Press, Inc., Boca Raton, Florida, 1990, pp. 331-332. 
${ }^{19}$ Rohloff, Thomas John, "Development and Evaluation of Neural Network Flush Air Data Sensing Systems," Ph.D. dissertation, University of California Los Angeles, 1998.

${ }^{20}$ Capone, Francis J., et al., The NASA Langley 16-Foot Transonic Tunnel: Historical Overview, Facility Description, Calibration, Flow Characteristics, and Test Capabilities, NASA TP-3521, 1995.

${ }^{21}$ Jackson, Charles M., Jr., William A. Corlett, and William L. Monta, Description and Calibration of the Langley Unitary Plan Wind Tunnel, NASA TP-1905, 1981.

${ }^{22}$ Gentry, Garl L., Jr., P. Frank Quinto, Gregory M. Gatlin, and Zachary T. Applin, The Langley 14- by 22-Foot Subsonic Tunnel: Description, Flow Characteristics, and Guide for Users, NASA TP-3008, 1990.

${ }^{23}$ Hoerner, Sighard F., Fluid-Dynamic Drag: Practical Information on Aerodynamic Drag and Hydrodynamic Resistance, self-published, 1965.
${ }^{24}$ Nowak, Robert J., Cindy W. Albertson, and L. Roane Hunt, Aerothermal Tests of a $12.5^{\circ}$ Cone at Mach 6.7 for Various Reynolds Numbers, Angles of Attack, and Nose Shapes, NASA TP-2345, 1985.

${ }^{25}$ Campbell, I. A., An Experimental and Numerical Study of Hypersonic Flow Over a Spherically Blunted $18^{\circ}$ Semi-Angle Cone, Australian Defence Scientific Service Aeronautical Research Laboratories, Aerodynamics Note 328, Sept. 1970.

${ }^{26}$ Passamaneck, R., Aerodynamic Characteristics of Spherically Blunted 45-Deg Half-Angle Cones, NASA TR-32-1327, 1968.

${ }^{27}$ Gera, J., R. J. Wilson, E., K. Enevoldson, and L. T. Nguyen, "Flight Test Experience with High- $\alpha$ Control System Techniques on the F-14 Airplane," AIAA-81$2505,1981$. 
Public reporting burden for this collection of information is estimated to average 1 hour per response, including the time for reviewing instructions, searching existing data sources, gathering and maintaining the data needed, and completing and reviewing the collection of information. Send comments regarding this burden estimate or any other aspect of this collection of information, including suggestions for reducing this burden, to Washington Headquarters Services, Directorate for Informatıon Operations and Reports, 1215 Jefferson Davis Highway, Suite 1204, Arlington, VA 22202-4302, and to the Office of Management and Budget, Paperwork Reduction Project (0704-0188), Washington, DC 20503.

1. AGENCY USE ONLY (Leave blank)

2. REPORT DATE

3. REPORT TYPE AND DATES COVERED

November 1999 Technical Paper

4. TITLE AND SUBTITLE

Flush Airdata Sensing (FADS) System Calibration Procedures and

Results for Blunt Forebodies

6. AUTHOR(S)

WU 242-33-02-00-23-00-TA3

Brent R. Cobleigh, Stephen A. Whitmore, Edward A. Haering, Jr.,

Jerry Borrer, and V. Eric Roback

7. PERFORMING ORGANIZATION NAME(S) AND ADDRESS(ES)

NASA Dryden Flight Research Center

P.O. Box 273

Edwards, California 93523-0273

8. PERFORMING ORGANIZATION

REPORT NUMBER

H-2379

9. SPONSORING/MONITORING AGENCY NAME(S) AND ADDRESS(ES)

10. SPONSORING/MONITORING AGENCY REPORT NUMBER

National Aeronautics and Space Administration

Washington, DC 20546-0001

NASA/TP-1999-209012

11. SUPPLEMENTARY NOTES

Presented at the 9th International Space Planes and Hypersonic Systems and Technologies Conference, November 1-5, 1999, Norfolk, VA, AIAA 99-4816. Brent R. Cobleigh, Stephen A. Whitmore, and Edward A. Haering, Jr., NASA Dryden, Edwards, California; Jerry Borrer, NASA Johnson, Houston, Texas; and V. Eric Roback, NASA Langley, Hampton, Virginia. A patent has been filed on this NASA invention. Equations (10)-(16) are included in this patent.

12a. DISTRIBUTION/AVAILABILITY STATEMENT

12b. DISTRIBUTION CODE

Unclassified-Unlimited

Subject Category 06

13. ABSTRACT (Maximum 200 words)

Blunt-forebody pressure data are used to study the behavior of the NASA Dryden Flight Research Center flush airdata sensing (FADS) pressure model and solution algorithm. The model relates surface pressure measurements to the airdata state. Spliced from the potential flow solution for uniform flow over a sphere and the modified Newtonian impact theory, the model was shown to apply to a wide range of blunt-forebody shapes and Mach numbers. Calibrations of a sphere, spherical cones, a Rankine half body, and the F-14, F/A-18, X-33, X-34, and X-38 configurations are shown. The three calibration parameters are well-behaved from Mach 0.25 to Mach 5.0, an angle-of-attack range extending to greater than $30^{\circ}$, and an angle-of-sideslip range extending to greater than $15^{\circ}$. Contrary to the sharp calibration changes found on traditional pitot-static systems at transonic speeds, the FADS calibrations are smooth, monotonic functions of Mach number and effective angles of attack and sideslip. Because the FADS calibration is sensitive to pressure port location, detailed measurements of the actual pressure port locations on the flight vehicle are required and the wind-tunnel calibration model should have pressure ports in similar locations. The procedure for calibrating a FADS system is outlined.

\section{SUBJECT TERMS}

Airdata calibration, Blunt forebody, FADS, Flush airdata sensing, Sphere, X-33, $\mathrm{X}-34, \mathrm{X}-38$.

17. SECURITY CLASSIFICATION OF REPORT

Unclassified
18. SECURITY CLASSIFICATION OF THIS PAGE

Unclassified
15. NUMBER OF PAGES

33

16. PRICE CODE

A03

20. LIMITATION OF ABSTRACT OF ABSTRACT

Unclassified
Unlimited 